\title{
Libros como trincheras. El Servicio de Lecturas del Soldado de la Biblioteca de la Universidad de Zaragoza durante la Guerra Civil (1936-1939)
}

\author{
Luis Blanco Domingo ${ }^{1}$
}

Recibido: 19 mayo 2017 / Aceptado: 20 de noviembre de 2017

Resumen. El Servicio de Lecturas para el Soldado fue un organismo impulsado por Miguel Artigas desde la Biblioteca de la Universidad de Zaragoza durante la Guerra Civil (1936-1939) como un instrumento más que contribuyera al triunfo militar del bando rebelde. El objetivo de este trabajo es analizar sus aspectos fundamentales: la difícil cohabitación con la actividad ordinaria de la biblioteca universitaria; la evolución de su funcionamiento y alcance; el papel de los facultativos y profesionales; y los resultados obtenidos, enmarcados dentro de un contexto en el que conviven las urgencias bélicas y una peculiar simbiosis entre los conceptos de lectura terapéutica y dirigida.

Palabras clave: Servicio de Lecturas para el Soldado; Guerra Civil; Bando sublevado; Miguel Artigas; Biblioteca de la Universidad de Zaragoza; Javier Lasso de la Vega; Aurea Javierre; Lectura dirigida.

\section{[en] Books as trenches. The Servicio de Lecturas del Soldado of the University Library of Zaragoza during the Civil War (1936-1939)}

\begin{abstract}
The Servicio de Lecturas para el Soldado was an organization promoted by Miguel Artigas from the University Library of Zaragoza during the Civil War (1936-1939) as one more instrument that contributed to the military triumph of the rebel forces. The objective of this work is to analyze its fundamental aspects: the difficult cohabitation with the ordinary activity of the university library; the evolution of its operation and scope; the role of librarians; and the results obtained, framed within a context in which war emergencies coexist and a peculiar symbiosis between the concepts of therapeutic and guided reading

Keywords: Servicio de Lecturas para el Soldado; Civil War; Rebel forces; Miguel Artigas; University Library of Zaragoza; Javier Lasso de la Vega; Aurea Javierre, Guided reading.
\end{abstract}

Sumario. 1. Introducción. 2. Conclusiones. 3. Referencias bibliográficas.

Cómo citar: Blanco Domingo, L. (2017) Libros como trincheras. El Servicio de Lecturas del Soldado de la Biblioteca de la Universidad de Zaragoza durante la Guerra Civil (1936-1939), en Revista General de Información y Documentación 27 (2), 433-470.

1 Universidad de Zaragoza. Departamento de Ciencias de la Documentación e Historia de la Ciencia E-mail:1mblanco@unizar.es 


\section{Introducción}

Durante los primeros compases de la Guerra Civil, Zaragoza, ciudad donde triunfó rápidamente el golpe de estado, se convirtió en el centro neurálgico de actuación del Cuerpo Facultativo de Archivos, Bibliotecas y Arqueólogos (CFABA), favorecida por acoger temporalmente en su Biblioteca universitaria a varios de sus miembros más significados, y sobre todo a los dos Inspectores Jefe, Miguel Artigas y Miguel Gómez del Campillo. Sin embargo, muy pronto hubo de abandonar los servicios tradicionales para transformarse en una fuerza de choque más, en un engranaje de la maquinaria bélica dirigido a satisfacer las demandas de las autoridades del ejército sublevado.

Una de los órganos instrumentales surgidos fue el Servicio de Lecturas para el Soldado, cuya trayectoria pretendemos analizar a lo largo de las siguientes páginas. Utilizando fundamentalmente fuentes archivísticas, se reconstruye una trayectoria que atravesó dos fases muy distintas: una primera hasta 1938 bajo la dirección de Miguel Artigas, caracterizada por la inestabilidad bélica, la presencia de normas ambiguas y genéricas y el protagonismo gestor de la biblioteca de la Universidad de Zaragoza; y una segunda articulada en torno a Javier Lasso de la Vega, cuyos rasgos más señalados son el tránsito de la capitalidad cultural a Vitoria, la concreción institucional de los Ministerios, y la redacción por parte de aquél de un exhaustivo reglamento de actuación del Servicio.

\subsection{EI nacimiento}

El Servicio de Lecturas para el Soldado tuvo sus orígenes durante la I Guerra Mundial, orientado a la consecución de tres objetivos fundamentales: facilitar un medio de distracción al soldado herido; influenciar y exaltar su ánimo combatiente por medio de lecturas dirigidas y debidamente filtradas, y por último, convertirse en el vehículo imprescindible de una actividad terapéutica novedosa, la biblioterapia, como complemento para la cicatrización no tanto de sus heridas físicas como mentales.

Durante la Guerra Civil, ambos bandos dispusieron de organismos que dinamizaron distintas actuaciones dirigidas a mejorar la situación anímica de los soldados tanto en los frentes de combate como en los hospitales que recibían a los heridos. Sin embargo, la eficacia y profundidad de los entes republicanos, tanto el gestionado por el Servicio de Cultura Popular desde Madrid², como el Servei de Bibliotheques del Front, creado por la Generalitat de Catalunya (Cugueró, M., Boada, M.T. y Allué, V., 2006: 67-112), superaban con creces la iniciativa del

2 En su constitución destacó sobremanera Teresa Andrés, funcionaria del Cuerpo Facultativo de Archiveros, Bibliotecarios y Arqueólogos tras ganar la oposición el 8 de agosto de 1931. Destinada primeramente al Museo Arqueológico de León, fue adscrita el 9 de septiembre del mismo año como jefa del Archivo del Palacio Real. Durante la guerra ocupó cargos de relevancia en el Ministerio de Instrucción Pública, desarrollando una intensa labor de extensión bibliotecaria y fomento de la lectura en frentes y hospitales, siendo la autora de un pequeño manual técnico, Indicaciones para la organización de bibliotecas de frentes, hospitales y cuarteles, Valencia: Cultura Popular, 1937, destinado a reglamentar la constitución y el funcionamiento de las mismas. Para ampliar su biografía, véase (Gómez Andrés, 2013). 
bando nacional amparada bajo el nombre de Servicio de Lecturas del Soldado (García Ejarque, 2000: 187 y ss.), no sólo por la menor implicación de los centros de poder y el escaso apoyo político recibido, sino también por la concepción de la lectura como una actividad perniciosa que debía ser sometida a rigurosas dosis de control y depuración antes de aceptarla, y el rechazo frontal a su virtualidad como canal educativo y de promoción social.

El Servicio de Bibliotecas Circulantes para Hospitales surgió por una iniciativa de Miguel Artigas, elevada a la Junta de Defensa de Burgos y aprobada por ésta en agosto de $1936 .{ }^{3}$ Pocos días más tarde se amplió a los frentes de combate. Y justo un año después, en agosto de 1937, el CFABA también asumiría la obra Lectura para el Soldado, creada por la Delegación de Prensa y Propaganda para aumentar la moral de los combatientes. ${ }^{4}$

La sección tenía como patrocinadora oficial a Carmen Polo, esposa de Franco. Esa referencia no era menor, puesto que de esa forma se aseguraba la aceptación y el respaldo de las autoridades, y evitaba cualquier duda sobre quién era el inductor y mecenas de la iniciativa.

La inestabilidad de la situación bélica en los primeros años de conflicto, una estructura administrativa supeditada a las necesidades militares y con escasa preocupación por la política cultural, y la dificultad de desarrollar una gestión activa y eficaz por parte de los facultativos que apoyaban el bando nacional, dispersos y en algunos casos ilocalizables, propiciaron que hasta enero de 1938 todas las actividades relacionadas con el Servicio de Lectura del Soldado fueran coordinadas desde la biblioteca de la Universidad de Zaragoza y asumidas por Miguel Artigas en su calidad de Inspector Jefe de Bibliotecas. ${ }^{5}$ A partir de esa fecha, las actuaciones serán responsabilidad de un emergente Lasso de la Vega, aupado por su estrecha relación con el ministro de Educación Nacional Sáinz Rodríguez, en detrimento de Artigas.

Quizá la presencia de Javier Lasso de la Vega en Portugal, y su tibia implicación inicial en apoyo de los sublevados, explique su no designación para dirigir el Servicio desde el principio, pese a su condición de máximo especialista en la materia. ${ }^{6}$

3 ABUZ. Memoria de la Biblioteca de la Universidad de Zaragoza 1936.

4 ABUZ. ARTIGAS, Miguel. Memoria sobre el Servicio de Lectura para el Soldado en Hospitales y Frentes. Zaragoza, 14 de mayo de 1938.

5 En el archivo de la BUZ hemos localizado una nota sin fecha ni remitente, pero dirigida a Artigas, en la que se le encarga oficialmente del servicio: Aprobada por la Junta Nacional de Defensa la iniciativa de crear y organizar bibliotecas circulantes para los hospitales militares y frentes dirigidas por el personal facultativo del Cuerpo de Archiveros, Bibliotecarios, teniendo en cuenta sus condiciones de inteligencia, moralidad, laboriosidad y patriotismo, he acordado designar a V.S. para la inmediata dirección en ese servicio que se centralizará en la biblioteca universitaria de esta ciudad. ABUZ. Comunicaciones oficiales. Nota dirigida a Miguel Artigas en la que le encarga la dirección del Servicio de Lecturas del Soldado. (s.f.).

6 Lasso de la Vega solicitó una subvención para acudir a los Estados Unidos a la Junta de Ampliación de Estudios en 1930, aprovechando la invitación que le había cursado la Spanish School of Middlebury para impartir unas conferencias en los cursos de verano de ese mismo año. El objetivo era estudiar la organización de la Biblioteca Pública de Nueva York. La petición fue atendida, y se le concedió la financiación de la estancia entre el 15 de junio y el 15 de septiembre. JAE. Expediente Javier Lasso de la Vega. JAE 84-80. Disponible en http://archivojae.edaddeplata.org/jae_app/ [Consulta: 16 de marzo de 2015]. Tras ello, dinamizó desde su Seminario de Biblioteconomía de la Universidad de Madrid a principios de los años 30, toda una serie de experimentos y prácticas relacionadas con la aplicación del valor terapéutico del libro y la lectura y la necesaria adaptación profesional de los bibliotecarios a una nueva actividad, convirtiéndose en un auténtico 
En septiembre de 1936, el propio Artigas dirigió una circular a los jefes de los distintos establecimientos que paulatinamente se iban conformando en el "territorio liberado", documento en el que se incluían normas para su organización. ${ }^{7}$ Tras señalar que la competencia y autoridad de los individuos del CFABA eran garantía de una necesaria y escrupulosa selección, marcaba las siguientes directrices de actuación:

1.- Anuncio en toda la prensa de la provincia solicitando el envío a la Biblioteca (universitaria o pública) de libros nuevos, usados o donativos en metálico para comprarlos.

2.- Difusión, a través de la radio, del fin perseguido, mediante una charla o por anuncios.

3.- Publicar en la prensa periódicamente listas de donantes.

4.- Llevar en la Biblioteca una relación-inventario muy sumaria de los libros recibidos.

5.- Los bibliotecarios tendrán especial cuidado de la selección de los libros.

6.- Sellar los libros con un sello distinto del corriente.

7.- Utilizar una sencilla papeleta como tarjeta de lector, guardada en la biblioteca.

8.- Listado de los libros enviados en cada lote a los hospitales, que podrán ser transferidos a otros centros tras su desinfección.

9.- Las enfermeras se convierten en las auxiliares de los bibliotecarios, siendo las responsables de las entregas y recogidas de los volúmenes.

10.- Las visitas personales de los bibliotecarios y señoritas visitadoras son imprescindibles para orientar a los enfermos en sus lecturas.

\subsection{Evolución y desarrollo}

Pocos días más tarde que en Zaragoza, empezaron a funcionar en Navarra, donde se repartieron unos 10.000 volúmenes, Málaga, León, Huesca. Salamanca, Valladolid, La Coruña, Teruel, Lugo, Ávila, Burgos, Soria, Logroño, Santiago de Compostela, y paulatinamente en todas las ciudades tomadas militarmente por el ejército rebelde. $^{8}$

En esta primera etapa, Miguel Artigas asumirá la coordinación del servicio en toda la zona ocupada por los sublevados. Poco tiempo después, un oficio del Jefe de Propaganda Nacional, el general Millán Astray, informaba de que se había procedido a la unificación de la obra Lecturas para el Soldado con la destinada a Bibliotecas para Hospitales, y le impelía a señalar las personas a las que debían entregar los materiales depositados en las Subdelegaciones de Prensa y Propaganda, haciendo especial hincapié en la situación de Sevilla, La Coruña y

pionero en España (Vall Casas, 1990: 303-319). En 1993 crearía un servicio circulante de Lecturas en el Hospital Clínico de Madrid cuando era director de la Biblioteca universitaria en 1933. El éxito de la experiencia le indujo a proponer su generalización a otros centros. (Marta TORRES, 2011: 155-160).

7 ABUZ. Circular a los jefes de establecimiento del Servicio de Lectura del Soldado. Septiembre de 1936.

8 ABUZ. ARTIGAS, Miguel. Memoria sobre el Servicio de Lectura para el Soldado en Hospitales y Frentes.

Zaragoza, 14 de mayo de 1938. 
Valladolid, "donde solamente en la primera población hay aproximadamente unos 25.000 ejemplares".

Artigas será por tanto quien designe a los facultativos responsables de la actividad en las localidades bajo la jurisdicción rebelde. ${ }^{10}$ Todos ellos se integraron, en calidad de agregados, a las Subdelegaciones Provinciales del Estado para Prensa y Propaganda en las provincias señaladas. La elección de Lasso para Sevilla resulta muy significativa, no tanto por el considerable volumen de trabajo a asumir, ni tan siquiera por su reconocida capacidad de gestión bibliográfica, sino porque en esta primera época se encuentra bajo las órdenes directas de Artigas, circunstancia que se va a modificar radicalmente tras la sustitución de la Junta Técnica por un esquema de gobierno más estable y reconocible a partir de enero de 1938.

Un informe de Miguel Artigas analiza, con fecha de 1 de abril, los resultados de las distintas provincias en las que se implantó el servicio. ${ }^{11}$ El siguiente cuadro refleja sus contenidos

Tabla 1.- Distritos del Servicio de Lecturas del Soldado

\begin{tabular}{|c|c|c|c|}
\hline Provincia & Responsables & Libros recibidos & Libros entregados \\
\hline Ávila & Pilar Loscertales & 765 & 150 \\
\hline Badajoz & Tomás Gómez Infante & \multicolumn{2}{|c|}{ Sin movimientos por ser heridos graves } \\
\hline Burgos & $\begin{array}{l}\text { Martínez } \\
\text { Burgos/Manuel } \\
\text { Machado } \\
\end{array}$ & \multicolumn{2}{|c|}{ No ha remitido partes } \\
\hline Cáceres & José Bueno & 661 & \\
\hline Cádiz & $\begin{array}{ll}\text { Rafael } & \text { Ricardo } \\
\text { O’Leary } & \end{array}$ & 1.591 & 311 \\
\hline Córdoba & Blas Taracena & 2.652 & 2.800 \\
\hline Coruña & $\begin{array}{l}\text { Carmen Roa /Salvador } \\
\text { Panga }\end{array}$ & 2.017 & 1.505 \\
\hline Granada & María Pardo & 1.976 & 2.012 \\
\hline Huelva & Carmen Nieto & 640 & 630 \\
\hline Huesca & $\begin{array}{ll}\text { Rosa } & \text { Rodríguez } \\
\text { Troncoso/Aurea Lóriz }\end{array}$ & 1.265 & 2.074 \\
\hline
\end{tabular}

$9 \quad$ ABUZ. Oficio de Millán Astray a Miguel Artigas, Inspector General de Bibliotecas sobre la unificación del Servicio de Lecturas para el Soldado con el destinado a las bibliotecas para hospitales. Salamanca 17 de agosto de 1937.

10 La Delegación de Prensa y Propaganda, con sede en Salamanca, solicita a Artigas información sobre las personas que han de encargarse del servicio en las diversas capitales de provincia en la que existen subdelegaciones de la misma. ABUZ. Oficio de la Delegación de Prensa y Propaganda a Miguel Artigas solicitando la relación de las personas dedicadas al Servicio de Lecturas del Soldado Salamanca, 13 de octubre de 1937. Contesta el 14 de diciembre del mismo año indicando que ya envío la relación con fecha 19 de octubre. ABUZ. Oficio de Miguel Artigas a la Delegación de Prensa y Propaganda sobre las personas dedicadas al Servicio de Lecturas del Soldado en la zona nacional, 14 de diciembre de 1937. El listado que proporcionó fue el siguiente: Javier Lasso de la Vega (Sevilla); Ricardo Magdaleno (Valladolid); Blas Taracena (Córdoba); Manuel Machado (Burgos); Salvador Parga Pondal (La Coruña); Carmen Jalón (León); Juan Irigoyen (Bilbao); Constantino Ballester (San Sebastián) y Carmen Pescador (Zamora)

11 ABUZ. Informe de Miguel Artigas sobre el Servicio de Lecturas del Soldado. Zaragoza, 14 de mayo de 1938 


\begin{tabular}{|c|c|c|c|}
\hline León & $\begin{array}{l}\text { Carmen Jalón/Ursicina } \\
\text { Martínez Gallego }\end{array}$ & 3.797 & 3.830 \\
\hline Logroño & Juana Molina Fajardo & 3.488 & $\begin{array}{c}386+\text { obras a censurar } \\
944\end{array}$ \\
\hline Lugo & Amalia Prieto & & 3.225 \\
\hline Málaga & Francisco Báguena & 6.000 & 4.992 \\
\hline Navarra & $\begin{array}{l}\text { Marcelo Núñez de } \\
\text { Cepeda }\end{array}$ & 11.500 & \\
\hline Orense & $\begin{array}{ll}\text { Datos } & \text { poco } \\
\text { sistemáticos } & \end{array}$ & & \\
\hline Oviedo & Igual que el anterior & & \\
\hline Palencia & Ramón Revilla & 282 & \\
\hline $\begin{array}{l}\text { Palma de } \\
\text { Mallorca }\end{array}$ & Miguel Ferrá & 1.057 & \\
\hline Pontevedra & $\begin{array}{ll}\text { Enrique } & \text { Fernández } \\
\text { Villamil } & \\
\end{array}$ & 2.808 & 2.808 \\
\hline Salamanca & $\begin{array}{l}\text { Fulgencio } \\
\text { Riesco/Asunción } \\
\text { Artigas }\end{array}$ & 800 & \\
\hline \multicolumn{4}{|l|}{$\begin{array}{l}\text { San } \\
\text { Sebastián }\end{array}$} \\
\hline $\begin{array}{l}\text { Santa Cruz } \\
\text { de Tenerife }\end{array}$ & Eduardo Champín & 80 & \\
\hline Santander & Sin datos & & \\
\hline Santiago & José $\mathrm{M}^{\mathrm{a}}$ Bustamante & & \\
\hline Segovia & Consuelo del Castillo & 2.047 & 330 \\
\hline Sevilla & Javier Lasso & 50.000 & 13.594 \\
\hline Soria & Agustín Ruiz Cabriada & 597 & 597 \\
\hline Teruel & Juan Giménez Bayo & 756 & \\
\hline Toledo & $\begin{array}{l}\text { Isaac Soler/Luisa } \\
\text { Gómez/Isabel Millé }\end{array}$ & & 850 \\
\hline Valladolid & $\begin{array}{ll}\text { Santiago } & \text { García } \\
\text { López/Ricardo } & \\
\text { Magdaleno } & \\
\end{array}$ & & 11.686 \\
\hline Vitoria & Antonio Mañueco & & \\
\hline Zamora & Carmela Pescador & 819 & 711 \\
\hline Zaragoza & Aurea Javierre & 29.096 & 19.791 \\
\hline
\end{tabular}

De los datos se pueden inferir algunas conclusiones: en primer lugar, el servicio fue extremadamente irregular, y no sólo por la movilidad de los frentes de combate. La escasez o inexistencia de referencias en algunas provincias refleja el escaso interés de los responsables por atender adecuadamente el servicio, o la imposibilidad de contar con las infraestructuras y apoyos adecuados. Las ambiguas normas elaboradas por Artigas propiciaron la existencia de un conglomerado heterogéneo y dispar en el que cada centro actuaba de forma autónoma, determinado por el interés y celo de los facultativos designados. Así, localidades 
como Burgos, Santander o San Sebastián no enviaron cifras sobre sus actividades, lo que contrasta con la capacidad gestora de Navarra, Zaragoza o Sevilla.

Las dos provincias más significadas en cuanto a capacidad organizativa del Servicio fueron Sevilla y Zaragoza. La primera, dirigida por Lasso de la Vega, ${ }^{12}$ estableció un sistema muy eficaz y racional, hábilmente estructurado y adaptado a las características de cada uno de los hospitales y frentes a los que debía atender. El numeroso fondo que había obtenido no sólo procedía de los donativos recibidos en las provincias que formaban parte de la $2^{\mathrm{a}}$ División Militar, sino también del Protectorado español en Marruecos.

Lasso dividió los hospitales en los siguientes grupos:
a) Hospital de sangre
b) De reconocimiento y convalecientes
c) Enfermedades graves o infecciosas
d) Enfermedades de la piel y sus anejos y
e) De moros

Tras alcanzar un acuerdo con las autoridades militares sanitarias, adaptó las actividades a la peculiaridad de cada hospital. Así, inició el servicio globalizado tan sólo en los del grupo a); en los b) y c) no se llevaron libros y se organizó únicamente la lectura diaria en voz alta. Al d) se le adjudicó un servicio mixto de circulación de revistas ilustradas y al e) narración de cuentos de zoco y lecturas apropiadas. ${ }^{13}$

Se realizaba un test a cada uno de los pacientes ingresados para averiguar su nivel cultural, aficiones, etc, con el objetivo de dotarles de los libros que les pudieran resultar más beneficiosos. Para los analfabetos, los que tenían problemas visuales o que por otras causas no podían leer, se organizaban lecturas en voz alta, complementadas con charlas y conferencias regulares de distinto tipo a cargo de personas eminentes. ${ }^{14} \mathrm{Se}$ organizaron visitas a los monumentos sevillanos para aquellos que podían salir a la calle, siempre contando con la autorización de los facultativos médicos. ${ }^{15}$

A pesar de su implicación y resultados, Lasso de la Vega no estaba satisfecho con su adscripción al Servicio. En una carta dirigida a Artigas, plantea la posibilidad de que, ante la presunta e inminente toma de Madrid, pudiera recuperar su antiguo puesto en la dirección de la Biblioteca de la Universidad Central. Expone que quizá fuera conveniente relevarle de sus funciones en el Servicio y

12 El nombramiento se produjo el 2 de septiembre de 1937. ABHMV. Fondo Lasso de la Vega. Oficio de Miguel Artigas a Javier Lasso de la Vega, Agregado a la Biblioteca Universitaria de Sevilla comunicándole su nombramiento como jefe del Servicio de Lecturas del Soldado del distrito de Sevilla. Zaragoza, 2 de septiembre de 1937.

13 ABUZ. Informe de Javier Lasso de la Vega a Miguel Artigas sobre el Servicio de Lecturas del Soldado en la provincia de Sevilla, Sevilla, noviembre de 1937

14 Ibidem

15 Ibidem. La mayor parte de las veces tenía como destinos la Catedral, el Museo de la ciudad y al Alcázar. 
designar a otra persona que concluyera la tarea sin ningún contratiempo ni alteración debida al curso de la guerra. ${ }^{16}$

Además, demanda el envío de instrucciones precisas para afrontar el servicio, sobre todo en los aspectos relativos a la cooperación con otros organismos como el ejército, la Delegación de Propaganda del Estado en la capital andaluza y el Auxilio Social para el Frente y Hospitales. ${ }^{17}$

$\mathrm{Su}$ celo profesional sin embargo le condujo a ampliar el servicio a las propias trincheras, donde se enfrentó a uno de los problemas constantes y que dificultarán considerablemente su alcance y difusión: la carencia de medios de transporte y la escasa implicación de los mandos militares para subsanarla. ${ }^{18}$ Consciente de la provisionalidad e improvisación que presiden el Servicio, traslada a Artigas algunas dudas sobre su funcionamiento. ${ }^{19}$

Las respuestas se producen una semana después. ${ }^{20}$ Respecto a la primera consideración, Artigas ve conveniente que las obras depuradas por la censura sean enviadas a la biblioteca universitaria para su control y gestión. En relación al posible conflicto competencial que se pudiera producir si extendiera su radio de acción, adopta una posición integradora, puesto que al mismo tiempo que le induce a evitar cualquier enfrentamiento, reconoce que la posición de Sevilla, al disponer de la mayor parte de los libros recibidos, le garantiza cierta preeminencia, que se ha

16 "He podido comprobar que se me mantiene al frente de este Servicio de Lectura para el Soldado y aunque lo desempeño con el máximo agrado e interés, creo de mi deber pedirle a Vd. Que considere si no sería muy conveniente que otro compañero adscrito permanentemente a esta ciudad debería sustituirme para que no se de el caso de que al tomar Madrid, si ello no concurriera con la terminación de la guerra, se encontraría el que hubiera de sustituirme con un servicio desconocido y planteado según normas que pudieran ser o no de su agrado. Yo le invito a Vd. a que medite sobre ello con el interés que Vd. pone al servicio de los problemas del Cuerpo y sin olvidar ni por un instante que estas consideraciones no significan en manera alguna deseo por mi parte de abandonarlo, sino al contrario servirlo con la máxima eficacia. Como podrá Vd. Comprobar por la firma de cuanta propaganda vengo haciendo en favor de este Servicio, los presto con absoluta reserva de mi nombre para evitar todo carácter personal". ABHMV. Fondo Lasso de la Vega. Carta de Javier Lasso de la Vega a Miguel Artigas sobre la posibilidad de ser relevado al frente del Servicio de Lecturas del Soldado. Sevilla, 23 de noviembre de 1937.

17 "Yo le estimaría muy cordialmente se sirva tener la bondad de darme instrucciones respecto a lo que debo hacer" Ibidem

18 "En este mes comenzaré el servicio de Bibliotecas de $2^{a}$ línea con circulación a trincheras, cosa que no he podido hacer hasta ahora, por falta de medios de traslado. Con verdadero sentimiento pude comprobar que hubo camiones y autos a granel para llevar turrones, coñac y vino y que yo llevo cuatro meses detrás de un vehículo en que llevar libros a los soldados, sin que me haya sido posible encontrarlo hasta ahora que al fin dispongo de él". ABHMV. Fondo Lasso de la Vega. Carta de Javier Lasso de la Vega a Miguel Artigas sobre el Servicio de Lecturas del Soldado. Sevilla 4 de febrero de 1938. Más adelante incluso propondrá como posible sustituto idóneo a José de la Peña y Cámara. ABHMV. Fondo Lasso de la Vega. Carta de Javier Lasso de la Vega a Miguel Artigas proponiendo como posible sustituto a José de la Peña y Cámara. Sevilla 17 de febrero de 1938.

19 Pregunta Lasso en primer lugar si considera Artigas que las obras estimadas por la censura como inadecuadas para distribuirlas a los soldados se remitan a la Biblioteca Universitaria para que allí decidan su destino final. En segundo lugar, si entra dentro de sus obligaciones servir los libros a los frentes de combate y los hospitales que se encuentren fuera de la zona jurisdiccional asumida por la Biblioteca de la Universidad de Sevilla, sobre todo teniendo en cuenta los posibles conflictos que pudieran surgir con el resto de los compañeros. ABHMV. Fondo Lasso de la Vega. Carta de Javier Lasso de la Vega a Miguel Artigas sobre el Servicio de Lecturas del Soldado. Sevilla, 17 de febrero de 1937.

20 ABHMV. Fondo Lasso de la Vega. Carta de Miguel Artigas a Javier Lasso de la Vega respondiendo a sus dudas sobre el funcionamiento del Servicio de Lecturas del Soldado. Zaragoza 24 de febrero de 1937. 
de traducir en acuerdos con otros funcionarios de Córdoba y Málaga para enviarles los libros que precisen.

Las intenciones que movieron a Artigas a implementar el servicio fueron diversas. Por un lado, reivindicar y destacar la profesionalidad de los funcionarios del CFABA, tratando de vencer la consideración que el Gobierno de Burgos tenía del mundo del libro, oscilante entre el recelo y la animadversión. ${ }^{21}$ Por otro, buscar la propia promoción profesional. Pero también perseguía establecer una red coherente de actuación que permitiera localizar a todos los facultativos en momentos de gran confusión, muchos de ellos ubicados en la zona republicana.

\subsection{Las peculiaridades zaragozanas}

En Zaragoza el Servicio empezó a funcionar el 31 de agosto de 1936. Siguiendo los preceptos expresados en la circular de Artigas señalada anteriormente, se envió una nota a la prensa solicitando la entrega de donativos, acompañada de una charla en Radio Aragón. La respuesta de los zaragozanos, a tenor de lo reseñado, fue espectacular, ya que la abundancia de libros permitió que una semana después empezara a funcionar el servicio, remitiéndose lotes a todos los hospitales establecidos en la capital, y alcanzando rápidamente la cifra de 11.000 volúmenes. ${ }^{22}$

Rápidamente se buscó la implicación de la Universidad en la difusión y propagación del servicio. Una nota de prensa del Rectorado informaba a los zaragozanos de su existencia, a los que trataba de seducir para que colaboraran a través de donativos, bien libros o en metálico, teniendo en cuenta los fines perseguidos. Señalaba además que haría pública la relación de aquellos que colaboraran, una hábil estratagema que satisface la necesidad de reconocimiento social y la búsqueda de una sólida coartada política que mostrara la adhesión a los sublevados. ${ }^{23}$

A partir de este momento, en reiteradas ocasiones aparecerán en los diarios zaragozanos listados de personas e instituciones que colaboran expresamente con el

21 En buena parte de las autoridades militares del ejército sublevado existía la convicción de que el escaso control sobre la edición de los libros había sido una de las causas determinantes del conflicto. Era necesario por tanto distinguir entre libros buenos y malos, condenando a estos últimos bien a su destrucción o a su desactivación en zonas especialmente señaladas en las bibliotecas, los llamados infiernos. El decreto de 23 de diciembre, publicado en el Boletín Oficial del Estado del día 24 del mismo mes, que declaraba ilícitas obras "de literatura pornográfica y disolvente" muestra esa aversión, ratificada en publicaciones como En el amanecer de España de Fernando García Montoto, uno de cuyos capítulos lleva el expresivo título de "Estupefacientes del alma (el libro y la prensa mal inspirados, germen del odio y de la destrucción revolucionaria)", o el propio artículo del rector Calamita (1936)

22 ABUZ. Memoria de la Biblioteca de la Universidad de Zaragoza, 1936.

23 “ En la Biblioteca Universitaria (Plaza de la Magdalena) se ha establecido el servicio de préstamo de libros a los Hospitales. Para este fin se admiten donativos en libros y en metálico en la Secretaría de esta Biblioteca de 9 a 1 de la mañana. Grandes consuelos puede producir un buen libro en el espíritu de un convaleciente. Todos tenemos en casa libros ya leídos que pueden tener ahora más que nunca un destino patriótico. En todas las editoriales, en todas las librerías hay siempre considerable número de volúmenes retirados de la venta; ningún español ni española negará unos céntimos para adquirir un libro que pueda causar distracción y llevar alegría a quienes han expuesto su vida por España.

Son varios y llegados por muy varios caminos ofrecimientos importantes y con el fin de organizar metódicamente este importante servicio se establece este préstamo que esperamos ha de hallar en donantes y en lectores una excelente acogida.

Se hará pública la relación de las personas y entidades que cooperen a este servicio. "Nota de prensa del Rectorado a los zaragozanos" Heraldo de Aragón, 2 de septiembre de 1936. 
Servicio, tanto a través de entregas en metálico para financiar su mantenimiento y ampliación como donando libros. ${ }^{24}$

La importancia estratégica de Zaragoza por su cercanía a unos todavía inestables frentes de combate, condicionó la elección de los responsables, de tal forma que el Servicio sólo fue desarrollado por personal del CFABA y alguna alumna de la Facultad de Filosofía y Letras bajo el estricto control de las autoridades militares, encargadas de supervisar y refrendar los nombramientos de sus integrantes. Al Delegado Militar de la $5^{\text {a }}$ Región Militar, comandante Pardo, se le encomendó la vigilancia y buen funcionamiento del organismo en el territorio que le competía jurisdiccionalmente. ${ }^{25}$

La dirección del Servicio fue asumida desde el primer momento por Aurea Javierre, ayudada por Clotilde Íñiguez, ${ }^{26}$ Ángeles Íñiguez ${ }^{27}$, Serafina Javierre ${ }^{28}$ y

24 "Se han recibido en la Biblioteca de la Universidad, con destino a los hospitales, donativos de libros de los señores siguientes: Don Ángel Pueyo, doña Pilar Marco, don Julián Conejero, don Prudencio Martín, doña Carmen Aspiroz, señorita María Jesús Caballero, doña Elena Ibáñez, don Luis Beneyto, don Juan Ilarri, don C. Sancho, Asociación de Maestros Católicos, director de la escuela Ramón y Cajal, Juventud Femenina de Acción Católica, señorita Carmen Serrano, El Eco de la Cruz, don Esteban Sancho Sala, don Carlos Sánchez Peguero. También se han recibido los siguientes donativos en metálico: Don Miguel López de Gera, 50 pesetas; recaudado en la Biblioteca, 28. Heraldo de Aragón, 21 de marzo de 1937. La publicación de "listas blancas" de donantes y suscriptores fue una práctica muy habitual en la retaguardia zaragozana como muestra de apoyo social a la sublevación, en este caso refrendada además con la presencia del alcalde López de Gera con una aportación en metálico. Para ampliar la conexión de la sociedad zaragozana con el bando nacional, véase ALCALDE FERNÁNDEZ (2010).

25 Una prueba de esa supervisión nos la ofrecen los impresos que, firmados por el propio comandante Pardo, se dirigían a los directores de los hospitales para que éstos eligieran un capellán del centro como encargado de la distribución, desinfección y petición de las nuevas obras requeridas por los heridos, debiendo dirigir su respuesta a la Delegación Militar como coordinadora del proceso. ABUZ, Servicio de Lecturas del Soldado. Oficios. Impreso dirigido a los directores de hospital por la Delegación Militar de la $5^{a}$ Región Militar sobre la elección del capellán como encargado de la gestión de los libros. La vinculación se mantiene hasta el 23 de julio de 1938, fecha en que se disuelve la Oficina de Prensa y Propaganda del $5^{\circ}$ Cuerpo de Ejército, y sus competencias pasan a ser asumidas por el Ministerio de Educación Nacional, siendo el interlocutor Pedro Sánchez Viejo en su calidad de director de la Biblioteca Universitaria de Zaragoza. ABUZ. Servicio de Lecturas del Soldado. Oficio del comandante Pardo dirigido a Aurea Javierre informando de que el interlocutor del Servicio pasa a ser Pedro Sánchez Viejo, director de la BUZ. Zaragoza 23 de julio de 1938.

26 Clotilde Íñiguez nace en enero de 1906. Licenciada en Farmacia, ingresa en el Cuerpo Auxiliar de Archivos, Bibliotecas y Museos el 9 de enero de 1933, con destino en el Archivo de Hacienda de Zaragoza. Al inicio de la contienda se encontraba en Sádaba disfrutando del permiso de verano concedido por la Biblioteca Nacional. Ese mismo día manifestó su adhesión al levantamiento militar en la propia localidad zaragozana, y en agosto de 1936 ante Gonzalo Calamita, Rector de la Universidad de Zaragoza. Fue adscrita desde su creación al Servicio de Lecturas al Soldado. A través de su expediente de depuración podemos comprobar que militó desde 1933 en Acción Popular. Sus testigos para refrendar todas las manifestaciones incluidas en el mismo fueron Julio Vidal Compairé, Nicolás Fernández Victorio y Ángela García Rives. El 31 de mayo de 1940 Miguel Gómez del Campillo concluye que continúe en el servicio sin imposición de ninguna sanción. AGA. Educación. Íñiguez Galíndez, Clotilde. Expediente de depuración. Caja 31/6059.

27 Según la Memoria de la Biblioteca de la Universidad de Zaragoza de 1938, falleció el 1 de diciembre de ese mismo año.

28 Serafina Javierre Mur, hermana de Aurea, nace el 24 de mayo de 1901. Ayudante interina de italiano en el Instituto de Zaragoza en 1930, donde había cursado el bachillerato. Profesora mercantil, ingresa en el Cuerpo Auxiliar de Archivos, Bibliotecas y Museos el 9 de enero de 1933. Destinada en el Archivo Histórico y de la Audiencia Territorial de Zaragoza, durante la guerra colabora activamente en el Servicio de Lecturas del Soldado, el servicio de información de heridos, el hospital de la Cruz Roja. Gómez del Campillo resuelve el expediente sin que le sea impuesta ningún tipo de sanción el 31 de mayo de 1940. Desarrolló buen parte de su carrera profesional en el Archivo de la Audiencia de Zaragoza. El 18 de abril de 1968 mediante concurso ocupa la plaza en el Servicio de Depósito Legal de Carlos Rodríguez Joulia-Saint Cyr, que fue destinado a la 
Ruth Quellemberg ${ }^{29}$. La primera era la única facultativa, siendo el resto del Cuerpo Auxiliar. Pero su implantación exigía la intervención constante del director de la biblioteca universitaria, y la dedicación de sus escasos efectivos en la dinamización de la obra. Esa forzada cohabitación condicionó sobremanera las actividades bibliotecarias, tanto por la labor de los facultativos como por el sobrecoste económico que supuso.

Las funciones encomendadas al director del centro, Pedro Sánchez Viejo, fueron extremadamente dispares, y contemplaron tanto las relaciones institucionales como la implicación directa en el propio funcionamiento del servicio. Así, solicitará en septiembre de 1936 al Estado Mayor de la 5a División Orgánica la relación de los establecimientos y hospitales donde radican heridos y enfermos para que se conviertan en los destinatarios de los donativos. ${ }^{30}$

El 24 de abril de 1937 Sánchez Viejo demandará al General Jefe de la 5a Región Militar el envío de los pases a los hospitales militares "sin restricción alguna", a todas las personas que integraban el Servicio en Zaragoza. ${ }^{31}$

Del mismo modo se dirige tanto a Falange como a los Requetés de Aragón para informarles de la existencia del Servicio y ofrecer libros a sus heridos. Ambos contestarán muy complacidos, y comunicando que van a designar personas de apoyo para agilizar el servicio. ${ }^{32}$

Junto con el Inspector de Bibliotecas Miguel Artigas, presentará al General de la $5^{\text {a }}$ División Orgánica, Miguel Ponte y Manso de Zúñiga, un informe de evaluación del servicio correspondiente al período comprendido entre el 1 de septiembre de 1936, hasta el 15 de enero de 1937, que resumimos en la siguiente tabla ${ }^{33}$

Biblioteca Nacional. Jubilada en 1971. AGA. Educación. Javierre Mur, Serafina. Expediente de depuración. Caja 31/6059.

29 Gustavo Alares revela que Ruth Quellemberg había sido colaboradora del Instituto de Estudios Medievales en Madrid. Desde 1940 trabajó como bibliotecaria en el Instituto de Historia Jerónimo Zurita del CSIC, que en 1939 sustituiría al primero. En 1943 formaba parte de la Escuela de Estudios Medievales de Zaragoza, y bajo la coordinación de José María Lacarra era la encargada de supervisar, junto a Carlos Corona, la elaboración de ficheros bibliográficos destinados a auxiliar a los alumnos de la Facultad de Filosofía y Letras. Durante la posguerra estuvo estrechamente vinculada a los servicios culturales de Falange. (ALARES LÓPEZ, 2007: p. X). Según José María Lacarra, publicó “Los mandatos reales de los reinados de Berenguer IV y Alfonso II". En Homenaje a Finke, Revista Zurita (1935), fasc. 3-4. aportación que sin embargo no ha podido ser localizada. (LACARRA., 1946: pp. 425-431).

30 El 25 del mismo mes Diego Gazapo, jefe de Estado Mayor de la División, le indica que forman parte de los mismos el Hospital Militar, Hospital Civil, Residencia de Estudiantes, Gran Politécnica Torres, Colegio de la Enseñanza, Facultad de Ciencias, Instituto Goya, Calatayud, Huesca, Teruel, Cruz Roja de Zaragoza. ABUZ. Oficio de Diego Gazapo, Jefe de Estado Mayor de la $5^{a}$ División, notificando a Pedro Sánchez Viejo los hospitales que forman parte de su jurisdicción. 25 de septiembre de 1936.

31 Incluía a Aurea Javierre, Clotilde Íñiguez, Ángeles Íñiguez, Serafina Javierre y Ruth Quellenberg, auxiliar de la Universidad de Zaragoza. 24 de abril de 1937. ABUZ. Servicio de Lecturas del Soldado Carta de Sánchez Viejo al General Jefe de la $5^{a}$ Región Militar. 24 de abril de 1937.

32 ABUZ. Servicio de Lecturas del Soldado. Carta de la sección provincial de Falange Española y de las JONS al Director de la Biblioteca Universitaria de Zaragoza comunicando el nombramiento de personas de apoyo al Servicio. 19 de septiembre de 1937 y ABUZ. Servicio de Lecturas del Soldado. Carta de los Requetés de Aragón al Director de la Biblioteca Universitaria de Zaragoza comunicando el nombramiento de personas de apoyo al Servicio. 19 de septiembre de 1937.

33 ABUZ. Servicio de Lecturas del Soldado. Nota presentada al General de la $5^{a}$ División Orgánica Miguel Ponte y Manso de Zúñiga por Miguel Artigas y Sánchez Viejo sobre la evolución del Servicio. 15 de enero de 1937. 
Tabla 2.- Volúmenes entregados a los hospitales del distrito de Zaragoza

\begin{tabular}{|l|l|c|}
\hline \multicolumn{1}{|c|}{ Localidad } & \multicolumn{1}{c|}{ Hospital } & Volúmenes \\
\hline Zaragoza & Militar & 621 \\
\hline & Costa y Refugio & 95 \\
\hline & Academia Torres & 213 \\
\hline & de la Enseñanza & 133 \\
\hline & Residencia de Estudiantes & 169 \\
\hline & Falange y Escolapios & 169 \\
\hline & Requetés & 110 \\
\hline & Provincial & 196 \\
\hline & Musulmán & 52 \\
\hline & Cruz Roja & 65 \\
\hline & Monte de Piedad & 56 \\
\hline Provincia de Zaragoza & Renovación & 50 \\
\hline & Alhama de Aragón & 134 \\
\hline & Monasterio de Veruela & 150 \\
\hline & Pedrola & 42 \\
\hline & Ateca & 70 \\
\hline Huesca & Sádaba & 30 \\
\hline Teruel & Ayerbe & 56 \\
\hline Guadalajara & Militar & 100 \\
\hline Toledo & Sigüenza & 50 \\
\hline TOTAL & Hospitales militares & 70 \\
\hline & & $\mathbf{2 . 6 3 1}$ \\
\hline
\end{tabular}

Además de estos lotes, se enviaron libros a los soldados que los solicitaron en los frentes de Campillo, Belchite, Huesca, Alerre, Fuentes de Ebro y Puebla de Alfindén.

Pocas son las observaciones que se adjuntan sobre la organización del servicio. El número de volúmenes disponible alcanza los 5.000 ejemplares. Todos los libros que pasaban por la biblioteca eran censurados y seleccionados por el personal del CFABA. En el tránsito de un hospital a otro, se sometían a una desinfección en el Instituto Provincial de Higiene.

La única consideración de orden técnico que acompaña al informe, concebida para optimizar la forma de actuación y mejorar la eficacia, se dirige a destacar la conveniencia de centralizar todos los envíos.

En el ámbito más directamente vinculado con aspectos organizativos, Pedro Sánchez Viejo realizó tareas de coordinación de la censura con que se saludaba a los volúmenes que llegaban a la Biblioteca, muchos de ellos "condenados" al denominado "infierno", 
lugar donde se almacenaban, registraban y conservaban las obras procedentes tanto de la Comisión Depuradora de Bibliotecas como de las donaciones. ${ }^{34}$

Del mismo modo, se encargaba de solicitar obras de difícil localización o servía de nexo de comunicación con otros organismos del régimen. El 10 de marzo de 1937 requiere a Sandro Machetti la remisión de obras escritas en italiano, puesto que entre los recibidos hasta ahora "no hay ninguno escrito en dicho idioma" ${ }^{35}$ Meses más tarde, redacta unas cartas al editor de la revista Letras para que envíe ejemplares de sus novelas, "precisamente la más solicitada por los heridos"36 y a José San Nicolás Francia pidiéndole ejemplares de su "patrióticas obra Alma nacional, leída con mucho agrado por los heridos"37

Un artículo publicado por Herráiz en El Noticiero sirve de plataforma propagandística para alcanzar uno de los objetivos señalados por el Servicio: persuadir a la población aragonesa de la necesidad de colaborar en tan encomiable empresa. Presenta una organización perfectamente coordinada, en la que la profesionalidad de los miembros del CFABA, a los que define como "magníficos vigilantes de la cultura", se convierte en elemento fundamental para evitar el tedio y mantener intacta la moral de la tropa. ${ }^{38}$

Desfilan por el artículo Miguel Artigas como coordinador de todas las actuaciones, el director de la BUZ, Pedro Sánchez Viejo, hombre de "extraordinaria competencia y cultura", y sobre todo Aurea Javierre, hilo conductor de la noticia y erróneamente considerada "bibliotecaria" del Archivo de la Corona de la Aragón. Pondera el autor del artículo que el éxito de la iniciativa surge de la combinación entre la profesionalidad y conocimientos técnicos de Javierre y su carácter piadoso y receptivo. Su implicación y esfuerzos le condujeron a realizar numerosas visitas a los hospitales para difundir todo aquello que los libros pueden aportar a los soldados convalecientes, hasta el punto de que la considera como la madrina de guerra de multitud de combatientes. ${ }^{39}$

34 "El señor Sánchez Viejo ejerce una escrupulosa censura en los envíos de libros. Nos muestra un rincón de la biblioteca que él califica de "El Infierno". Los donativos de libros pasan por el vigilante tamiz de la mirada inquisitorial del director de la biblioteca. Toda la literatura deprimente, llena de blandenguerías pacifistas que disimulaban el imperialismo de Moscou; la torpe ola de literatura pseudo-científica, una forma más de la subversión comunista que ensuciaba los escaparates de las librerías, es sistemáticamente apartada de los envíos de libros". HERRÁIZ (1937)

35 ABUZ. Servicio de Lecturas del Soldado. Carta de Pedro Sánchez Viejo a Sandro Machetti solicitando obras en italiano para el Servicio. 10 de marzo de 1937.

36 ABUZ. Servicio de Lecturas del Soldado. Carta de Pedro Sánchez Viejo al editor de la revista Letras para que envíe ejemplares de sus novelas para el Servicio. 27 de septiembre de 1937.

37 ABUZ. Servicio de Lecturas del Soldado. Carta de Pedro Sánchez Viejo a Joaquín San Nicolás Francia para que remita ejemplares de su obra Alma Nacional con destino al Servicio. 28 de septiembre de 1937. Se trata de la obra Alma Nacional: canciones de guerra y paz. Zaragoza: Heraldo de Aragón, 1937, una selección de las poesías publicadas por el sacerdote aragonés en las páginas del diario en las que proclama la absoluta adhesión y fidelidad de la Iglesia católica a Franco. (MELERO, 2006)

38 "Libros para llenar las horas abrumadoras de tedio de los hospitales; las horas de los parapetos, cuando la vigilia tensa agota más que la lucha. El ilustre director de la BN, don Miguel Artigas, y con él todo el Cuerpo de archiveros y bibliotecarios han puesto al servicio de esta idea toda su erudición y entusiasmo. Nadie como ellos, magníficos vigilantes de la cultura, podía comprender mejor la necesidad de cumplir esta piadosa tarea que hace llegar la voz amiga del libro a las salas de los hospitales y a las trincheras. Ellos, para quienes el libro es un poco el pan nuestro de cada día, sabían que nuestros soldados querían leer, y que la Patria no podría privar a sus mejores hijos del amable regalo de la lectura". HERRÁIZ (1937) 
La experiencia de Javierre se traduce en el perfecto conocimiento de las preferencias literarias de los lectores, según nos refiere el articulista. Y tratando de mostrar el lado amable de uno de los cuerpos de choque más celebrados y temidos del bando nacional, los legionarios, ofrece una grotesca y raramente creíble visión de su atracción por la novela rosa debido a que "desprecian la noche de aventuras porque su vida, densa de vigor y de emociones, les brinda aventuras superiores a las que pueda narrarles la imaginación de cualquier escritor", siempre y cuando puedan camuflar sus lecturas al tratarse de "lecturas de señorita" de difícil vinculación a su espíritu aguerrido. ${ }^{40}$

Las novelas de aventuras son las más solicitadas. Javierre interpreta que, con su elección, los soldados pretenden recuperar aquellos héroes que les acompañaron en su infancia. ${ }^{41}$

Con el objetivo de evitar una percepción excesivamente frívola y superficial tanto del Servicio como de los propios combatientes, Herráiz revela peticiones de mayor calado intelectual, quizá fabuladas, como la de un campesino aragonés que había pedido Fausto de Goethe y Lo bello y lo sublime de Kant. Tampoco podían faltar libros de tenor patriótico o religioso: "Las Confesiones de San Agustín es otra de las obras más solicitadas y, desde luego, los Episodios Nacionales es una de las lecturas preferidas. Hubo algún soldado que solicitó las obras de Mella sobre la Eucaristía". 42

Javierre aprovecha la posible repercusión social del artículo para solicitar la entrega de dinero en metálico destinado a la adquisición de aquellas colecciones y obras de las que carezcan. ${ }^{43}$

\subsection{El espejo sevillano}

La ascendencia intelectual de Lasso de la Vega y sus ideas para dinamizar el Servicio de Lecturas en Sevilla influyeron notablemente sobre la sede zaragozana. Consciente de la enorme dificultad que suponía conseguir el número de obras suficientes para atender todos los centros bajo su jurisdicción, paulatinamente ampliados conforme avanzaban las tropas nacionales, Aurea Javierre solicitó la autorización necesaria para organizar sesiones de cine cuya entrada consistiera en la entrega de un libro que de este modo garantizara el aumento del fondo bibliográfico, siguiendo el modelo ya experimentado en Sevilla gracias a la iniciativa de Lasso. ${ }^{44}$

$40 \quad$ Ibidem

41 "Recordar las viejas lecturas heroicas de la niñez para volver a vivir las ilusiones de los días ingenuos. Otra vez Buffalo Bille, el buen amigo, señor de las praderas, volverá a cabalgar en éxtasis sobre el rumor heroico de la guerra, Pico de Águila, Sandokan, el capitán Nemo ... voces antiguas de la infancia, apagadas y lejanas, volverán a narrar a nuestros soldados bellas rutas de valor y honor. Los camaradas inolvidables de nuestras primeras lecturas irán a las trincheras a conversar con sus viejos amigos ... Para que los soldados españoles encuentren a sus heroicos amigos entre estos vientos de cruzada." Ibidem

42 Ibidem

43 Ibidem

44 ABUZ. Servicio de Lecturas del Soldado. Informe de Javierre al Subdelegado de Prensa y Propaganda sobre el Servicio de Lectura. Zaragoza 14 de septiembre de 1937. 
En cuanto a las materias de las obras a disposición de los heridos, marcaba una doble dirección. Por un lado los libros de aventuras. ${ }^{45}$ Por otro, y con el objeto de conferir a las bibliotecas de un carácter educativo y adoctrinador, consideraba muy conveniente disponer de colecciones de autores clásicos y obras de enaltecimiento patriótico que modelaran las conductas. Apostaba con ello por la especialización de las obras recogidas, evitando aquellas de contenido pornográfico o que estuvieran incompletas. El sesgo y la militancia católica de Javierre quedan por tanto perfectamente reflejado el marcar las excepciones que debían acompañar la selección de los libros. ${ }^{46}$

Como medio de evaluar la capacidad del servicio se realizaban visitas de inspección dirigidas y coordinadas por Aurea Javierre. En el informe que redactó tras su periplo por los hospitales militares de Alhama de Aragón, Ateca y Calatayud, constata una de las principales dificultades que inciden negativamente en la eficacia y alcance de la actividad: la incapacidad para asegurar los envíos. Los problemas de logística y transporte fueron una constante imposible de soslayar, afectada tanto por la propia precariedad de las redes viarias como por la conciencia de subsidiariedad que el servicio tenía para unas autoridades absorbidas absolutamente por la consecución de la victoria militar. No sorprende por tanto que el Hospital de Ateca no hubiera recibido ninguno de los paquetes dirigidos desde la Biblioteca, que contenían en origen 273 volúmenes entre libros y revistas, a pesar de disponer de todos los resguardos entregados en la oficina de correos de forma reglamentaria. Para tratar de remediar la situación, Javierre dispone una nueva entrega de 111 obras, indicando mediante un oficio al director del hospital que en caso de que no se recibieran en un tiempo prudencial se lo comunique para realizar la reclamación pertinente. ${ }^{47}$

No obstante, también se congratula del éxito que experimenta tanto en Alhama de Aragón como en Calatayud. En la primera localidad se dispone de un fondo de 450 volúmenes, que se distribuyen entre los hospitales de la Cascada, Parque y San Fermín gracias al celo y la dedicación del padre Jacinto Molina, secundado por dos capellanes castrenses. Consecuencia del continuado uso de los libros, muchos de ellos fueron retirados y sustituidos por una nueva remesa de 333 que personalmente entregaría la propia Aurea a los heridos. Por su parte, los dos hospitales de Calatayud (Cruz Roja y Hospital Militar) carecían de libros suficientes para atender la demanda existente, circunstancia que se intenta paliar ofreciendo nuevas obras.

Debido a que la mayor parte de las peticiones se dirigen a la lectura de libros de aventuras, Aurea manifiesta el agotamiento de las existencias de obras de ficción, por lo que de nuevo insiste en la necesidad de organizar sesiones de cine que

45 "sobre todo de la colección Molino (series azul y oro)", cuyas peticiones no se podían afrontar debido a que se hallan agotados todos los recibidos "y no haber existencia de ellos en las librerías" Ibidem

46 Para ampliar contenidos sobre su pensamiento católico, véase (BENÍTEZ MARCO, 2014: 159-188).

47 ABUZ. Servicio de Lecturas del Soldado. Visita realizada por Aurea Javierre el 21 de septiembre de 1937 para inspeccionar los servicios de la obra Lectura para el Soldado en los Hospitales Militares de Alhama de Aragón, Ateca y Calatayud 
posibiliten el incremento del contingente de obras y satisfacer de esta manera las demandas de los heridos. ${ }^{48}$

Paralelamente al avance del ejército sublevado y a la mayor estabilidad de las fronteras, la actividad se fue extendiendo a los hospitales de toda la provincia de Zaragoza, a Huesca, Teruel, Guadalajara, Soria y Toledo. La iniciativa se amplió a los frentes de campaña, enviándose en una primera fase libros de forma individualizada a los soldados que lo solicitaban, hasta que en un segundo momento se organizaron bibliotecas circulantes con carácter regular en los frentes dependientes de la $5^{\text {a }}$ División. Los jefes y oficiales de las distintas columnas que conformaban el ejército eran los encargados de distribuir los ejemplares entre sus efectivos. La memoria se hace eco del enorme entusiasmo con que fue recibida esta idea por parte de los soldados a través de la correspondencia mantenida con los mismos. Además, se atendían las peticiones individuales que, por vía postal, llegaban a la biblioteca.

La censura y la distribución directa de los libros fueron dos de los elementos fundamentales sobre los que se sustentaron las lecturas dirigidas. Sin embargo, no deja de resultar curioso y hasta contradictorio que muchas de las obras entregadas y autorizadas para su circulación a los frentes y hospitales coincidan con las que simultáneamente estaban siendo depuradas y retiradas de los fondos de las bibliotecas por la Comisión Depuradora del Distrito Universitario de Zaragoza. Ello muestra, más allá de un evidente descontrol fácilmente atribuible al marasmo provocado por la guerra, la inexistencia de normas claras y precisas sobre qué obras se consideraban impropias o perjudiciales, lo que obligaba a aplicar criterios subjetivos en la selección. La obsesión por desmontar la obra pedagógica de la Institución Libre de Enseñanza provocaba que la totalidad de los fondos que integraban las Bibliotecas de Misiones Pedagógicas fuesen objeto de depuración, independientemente de sus contenidos o de la intencionalidad política del autor. La mera presencia de un sello que los vinculara con las mismas suponía un estigma imposible de soslayar. Incluso se perseguían editoriales como Espasa-Calpe, a quien se demandaba la necesidad de purificar su catálogo por contener títulos condenados por la Iglesia como el Discurso del Método de Descartes o La rebelión de las masas, de Ortega y Gasset. ${ }^{49}$

Autores como Wells, Zamacois, Wilde, Pardo Bazán, Palacio Valdés o Verne difícilmente superarían el filtro de la Comisión, y sin embargo, proliferan en los listados admitidos para integrar el fondo susceptible de ser solicitado tanto por los frentes como por los hospitales. Ello sin tener en cuenta la sorprendente presencia de obras como el Manifiesto comunista de Marx, El contrato social de Rousseau o Mariana Pineda de García Lorca.

Del mismo modo, también numerosos títulos teóricamente "disolventes" o "nocivos", procedentes de las distintas sesiones cinematográficas organizadas tanto por el Servicio de Lecturas como por la Delegación de Prensa y Propaganda adquieren gran protagonismo en los listados que se suministran para satisfacer las

$\begin{array}{ll}48 & \text { Ibidem } \\ 49 & \text { MARTÍNEZ RUS, 2014: } 19\end{array}$ 
peticiones de los usuarios del servicio. Muchos de ellos proceden de la colección La novela de hoy, novelas cortas y fácilmente digeribles, heterogéneas en cuanto a sus contenidos, pero con algún relato cercano a la literatura erótica, y presididas por un agudizado componente naturalista influenciado por la obra de Zola.

La explicación de la mayor permeabilidad y laxitud de los criterios censores adoptados en la Biblioteca de la Universidad de Zaragoza frente a los más restrictivos que asume la Comisión Depuradora pudiera deberse a la urgencia de disponer de una selección amplia y en constante renovación, amén de que la propia celeridad con la que transcurrían los acontecimientos y el numeroso trabajo que debían afrontar, con un personal escaso y en un amplio porcentaje escasamente preparado, dificultaba las tareas de control.

Desde el punto de vista bibliográfico, en los libros donados por los particulares sólo se consigna el título, mientras que en los entregados por la Delegación de Prensa y Propaganda aparecen organizados por autor-título. Todos ellos sin embargo disponen los registros de forma abreviada, con escasa información, convirtiéndose en meros inventarios de títulos estructurados de forma cronológica, y organizados mediante números currens, muy en consonancia con el objetivo de ofrecer instrumentos ágiles para un consumo administrativo rápido.

Cada biblioteca circulante poseía un catálogo de libros propio, clasificado por materias, del que se servían varias copias para que los potenciales usuarios pudieran elegir la obra que más les interesara. Tras ser reintegrados a la Biblioteca, y antes de ser puestos de nuevo a disposición de los soldados, eran cuidadosamente desinfectados en el Laboratorio Provincial de Higiene.

Los libros iban acompañados de un faldón en el que se podían leer una serie de recomendaciones que procuraban, en un claro tono paternalista, evitar el entorpecimiento del servicio por malos hábitos debidos a los lectores. ${ }^{50}$

Se imprimieron fichas de préstamo para conocer y controlar el destino de las obras, en las que se rellenaban los campos Nombre del lector; Hospital; Sala, cama $\mathrm{n}^{\mathrm{o}} \mathrm{y}$ número de inventario identificador del libro en cuestión.

De forma extraordinaria, se suministraron fondos al Orfanato de Guerra de Tarazona, la Escuela de Sargentos de Cortes y al General Emilio Mola, Jefe de la Zona Norte. El primero recibió el día de reyes cuentos infantiles, mientras que el envío al general Mola de un "selecto" lote de libros para que se incorporaran a la Biblioteca de su Cuartel General tuvo como motivación mostrar la gratitud al constante interés que mantuvo por la tarea desempeñada por el Servicio. ${ }^{51}$

50 "Lector: devuelve este libro después de leerlo, otro enfermo lo espera. Tú puedes leer los que otros han leído ya.

Lector: piensa que estos libros son para todos los enfermos y heridos

Lector: libro estropeado o sucio es libro perdido

Lector: los libros son para los enfermos; dejarlos salir del Hospital o sacarlos es una mala acción”. ABUZ. Servicio de Lecturas del Soldado.

51 En una nota manuscrita dirigida al Comandante Militar de Jaca, Sánchez Viejo le comunica que "atendiendo el deseo del Excmo. Sr. D. Emilio Mola, general Jefe del Ejército del Norte, de que se establezcan bibliotecas circulantes en los frentes, esta Biblioteca tiene el gusto de enviar a V. 7 paquetes que contienen 152 volúmenes con destino a las secciones dependientes de su mando. ABUZ. Correspondencia oficial. Nota de Pedro Sánchez Viejo al Comandante militar de Jaca comunicando el envío de libros al general Mola. 


\subsection{La labor organizativa de Aurea Javierre}

Es imposible realizar un análisis preciso y certero de la suerte del organismo en la capital del Ebro sin referirse a la actividad de Aurea Javierre. Su celo profesional y dinamismo la convertirían en la piedra angular del mismo, circunstancia que no pasará inadvertida para Lasso de la Vega quien, en calidad de Jefe de Archivos, Bibliotecas y Museos desde el año 1938, utilizará los conocimientos y la experiencia adquiridos por Aurea en su reducto zaragozano para asignarle otros cometidos, e incluso considerarla la candidata más idónea para dirigir una hipotética Dirección Nacional del propio Servicio.

Durante la guerra civil estuvo muy vinculada a la Biblioteca de la Universidad de Zaragoza y al propio Servicio de Lecturas. ${ }^{52}$ Javierre "prestó adhesión al Movimiento desde su iniciación", y antes de presentarse conjuntamente con Miguel Artigas ante el rector Calamita en agosto de 1936 en la Universidad de Zaragoza, trabajó confeccionando prendas para los soldados. Desde primeros de septiembre de 1936 asumió la organización del Servicio en el territorio controlado por el $5^{\text {a }}$ Cuerpo del Ejército, centralizado en Zaragoza, pero que progresivamente, y merced al avance militar de las tropas sublevadas, fue incorporando a su jurisdicción Castellón y Lérida.

En mayo de 1937 se le ordenó trasladarse a San Sebastián para dinamizar allí el Servicio. A finales de 1937, y hasta el mes de abril de 1938, simultaneó sus tareas con el trabajo en la Auditoría del Ejército de Ocupación en Zaragoza. Más tarde, se integrará en el Servicio de Defensa del Patrimonio Artístico Nacional. ${ }^{53}$

En septiembre de ese mismo año, Lasso de la Vega le notifica que debe contactar con Lluis Revest y Miguel Agelet, facultativos encargados del Servicio en las provincias de Castellón y Lérida respectivamente, para que les informe de la situación en que se encontraba, y al mismo tiempo remitirles alguna dotación de libros con la que pudieran comenzar a atenderlo. ${ }^{54}$ Javierre les solicita información sobre el número y condiciones de los hospitales existentes en las localidades para de esta forma estimar el fondo bibliográfico que precisarían. Sólo tenemos noticias de la respuesta de Revest, quien le notifica que disponen de cuatro, si bien existen muchas posibilidades de añadir uno más, para un número de hospitalizados mayor de 2.000 , sin contar con los seis o siete provinciales, entre los que incluye los situados en Vinaroz y Villafranca. ${ }^{55}$

Zaragoza, 10 de febrero de 1937. En el anexo IV se incluyen el número de volúmenes solicitados por los combatientes de forma individual y los enviados a las zonas de los frentes. Véase Anexo IV.

52 AGA. Educación. Aurea Javierre Mur. Expediente de Depuración. Caja 31/6055, n 14068-2-32

53 ABUZ. Correspondencia oficial. Oficio de Gómez del Campillo a Javierre sobre la disposición del documento de identidad como asesor auxiliar de la Defensa del patrimonio Artístico Nacional. Vitoria 15 de diciembre de 1938.

54 ABUZ. Correspondencia oficial. Oficio de Lasso de la Vega a Aurea Javierre para que contacte con los señores Revest y Corzo y Agelet Gosé encargados del Servicio de Lecturas del Soldado en las provincias de Castellón y Lérida. Vitoria 3 de agosto de 1938.

55 ABUZ. Correspondencia oficial. Oficio de Lluis Revest y Corzo a Aurea Javierre sobre el número de hospitales bajo su jurisdicción. Castellón, 23 de septiembre de 1938. 
Tras alguna pequeña fricción por un tema de competencias, ${ }^{56}$ en enero de 1939 se le ordena dirigirse a Barcelona con el objetivo de coordinar el Servicio, hasta que el 5 de julio de 1939 se incorpora al Archivo Histórico Nacional de Madrid. ${ }^{57}$

Las ideas que impulsaban su voluntad de actuación están perfectamente definidas. ${ }^{58}$ Justifica la entrega de libros a los soldados no sólo por un aspecto puramente terapéutico o para facilitar su evasión, sino como un acto de justicia y homenaje "hacia los bravos defensores de España".

Otra de sus líneas argumentales resulta extremadamente significativa por lo que supone de acercamiento a la pretensión, iniciada por Artigas primero y más tarde asumida por Lasso de la Vega, de reivindicar el necesario papel que ha de asumir el CFABA en el proceso de construcción del Nuevo Estado. Para ello, no duda en aprovecharse de la fortaleza retórica de la imagen de continuidad histórica que representa la "Cruzada", y del necesario protagonismo del ente en el control documental y legitimador del proceso. Ellos son los encargados de custodiar los archivos que conservan los documentos en los que se basa la historia de España, mientras que las bibliotecas la difunden y divulgan. ${ }^{59}$

La fórmula del éxito de la iniciativa pasaba necesariamente por la aportación de libros y revistas. Por ello demanda el apoyo de los aragoneses, a los que intenta seducir apelando a su vertiente más sentimental, patriótica e incluso religiosa. Para Javierre, la lectura se convierte no sólo en un bálsamo capaz de distraer a los heridos y ofrecerles solaz y esparcimiento en momentos de sufrimiento, sino que también se presenta capaz de elevar la moral y el ánimo de las tropas. Por ello, más allá de la entrega de libros ya leídos o poco utilizados, valora extraordinariamente la aportación, como si de una ofrenda se tratara, de otros que guarden una estrecha relación sentimental con sus donantes. ${ }^{60}$

Como refuerzo y medida de persuasión hacia las autoridades, enumera una serie de ejemplos basados en su experiencia, buscando conmover a todo aquel que se acerque a su informe. ${ }^{61}$

56 Pareció existir cierto exceso de celo en los cometidos que asumió Javierre con respecto a la organización del servicio en Castellón, hasta el punto de que el propio Lasso le envía un oficio en el que censura su grado de implicación, y concluye que es a él a quien compete mandar instrucciones. ABUZ. Correspondencia oficial. Oficio de Lasso a Aurea Javierre sobre el límite de sus competencias territoriales. Vitoria 21 de octubre de 1938.

57 AGA. Educación. Aurea Javierre Mur. Expediente de Depuración. Caja 31/6055, n 14068-2-32. La resolución firmada por Miguel Gómez del Campillo el 27 de mayo de 1940 es de no aplicar ninguna sanción. Actuaron como testigos el archivero y sacerdote Benito Fuentes Isla, quien fuera en 1942 nombrado Inspector General de Archivos y en 1945 Director del Archivo Histórico Nacional; Antonio de Torres Gasión, director accidental del Archivo Histórico Nacional en 1937 en el Madrid republicano; y Nicolás Fernández Victorio.

58 ABUZ. JAVIERRE, Aurea. Informe sobre el Servicio de Lecturas del Soldado (s.f.)

59 [sin ellos] " nadie podía comprender mejor lo que hay de continuidad histórica en esta magnífica Cruzada" Ibidem

60 "Cuando nuestros soldados tan generosamente ofrecen su vida por la patria, no podemos regatear unos libros que distraigan sus dolores y endulcen su soledad. Si la lectura es siempre prenda inestimable mucha más lo será para los heridos en quienes todos los dolores toman cuerpo y presencia. Cuando sufre, el hombre vuelve con más reiterado afán sus ojos y su espíritu hacia los libros. Sujeta entre sus páginas, la imaginación, que el dolor exalta, reposa y el ánimo se templa y fortalece. Todos tenemos obras ya leídas que sin gran sacrificio podemos ofrecer y acaso me atrevería a pedir alguna de las amorosamente guardadas para que nuestra ofrenda tuviese además un valor espiritual" Ibidem

61 "Ayer un soldado a quien la fiebre impedía leer me rogó que dejase sobre su mesa una novela. Poco después era trasladado de sala y lo primero que pidió fue que le llevasen su libro. Todos los reciben con verdadera 
Las obras que despertaban mayor interés eran las novelas de aventuras, como las escritas por James Oliver Curwood, Stevenson, Wallace, Peter Kins, o Zane Grey. También señalaba las novelas de Emmuska Orczy, autora de La Pimpinela Escarlata, y aquellas que contenían tramas policiacas capaces de captar la atención y el interés de unos lectores necesitados de evasión. Ya en menor medida, aparecían libros de viajes, épica caballeresca o novela costumbrista. ${ }^{62}$

En un segmento menos significativo se incorporan grandes clásicos de la literatura española (Lope de Vega, Calderón o Cervantes). Los poetas predilectos son Zorrilla, el Duque de Rivas, Espronceda, Rubén Darío, Gabriel y Galán y los Machado. También aparecen Valera, Alarcón, Pereda, Palacio Valdés, Pérez Lugín o Benavente, cuya popularidad para Javierre se debe sobre todo a su trágico final; los cuentos de Trueba y Fernán Caballero, y de manera más esporádica y extraordinaria las novelas cortas y piezas teatrales sin grandes complicaciones, sobre todo los mosaicos populares y castizos compuestos por Arniches y los hermanos Quintero. ${ }^{63}$

Tampoco desdeña las novelas históricas o el género biográfico, cuya enumeración aprovecha para deslizar comentarios épicos sobre el aspecto heroico y glorioso de su combate en "otra guerra de independencia", haciéndoles sentir protagonistas de un hecho a través del cual "la historia recoge y glorifica sus dolores" preeminente de los Episodios Nacionales de Pérez Galdós resulta paradójica, por cuanto la Comisión Depuradora de Bibliotecas había retirado de la consulta y circulación prácticamente toda su obra aduciendo razones morales.

Concluye lanzando una petición que se convertirá en una constante: la entrega ininterrumpida de libros para atender no sólo a los hospitales de Zaragoza, sino a los de su provincia y los de todas las localidades que transitoriamente se incorporan a su jurisdicción. Hace un especial llamamiento a la mujer aragonesa, "tan exquisitamente probada en estos momentos" para que colabore de forma activa en "esta magna obra de resurgimiento nacional". ${ }^{65}$

alegría: yo quiero una novela de aventuras, dice un soldadito (casi un niño), porque soy muy aventurero y un bravo legionario que a su lado convalece de una terrible herida, pide una novela histórica, porque las aventuras, dice, prefiero vivirlas. No falta tampoco el soldadito ingenuo, que con la mirada un poco lejana pensando acaso en la novia ausente, tímidamente pregunta ¿Podría Vd. traerme una novela de amor?” Ibidem

62 "Son también muy solicitados los libros de viajes a través de cuyas páginas la misteriosa emoción de lo desconocido distrae el espíritu sin fatigarlo, las finas historias caballerescas en las que aparece la fisonomía de la edad media con sus luchas y sus inquietudes y nuestra incomparable novela de costumbres llena de gracejo y de color" Ibidem

63 Ibidem. Curiosamente, en esta breve relación de autores figuran algunos que, como Valera o Palacio Valdés, veían retiradas sus obras por las Comisiones Depuradoras de los Distritos Universitarios. Incluso causa mayor sorpresa comprobar la presencia de Antonio Machado, aunque sea de forma implícita con la fórmula "los Machado".

64 "Piden nuestros soldados con frecuencia biografías de personajes ilustres, héroes y santos y lecturas históricas que narren y comenten los grandes hechos que trazaron el camino de la humanidad. Entre éstas, les interesan extraordinariamente las primeras series de los Episodios Nacionales de Pérez Galdós. No sólo son frecuentemente solicitadas sino que su lectura es muy oportuna en estos momentos. Cierto que no necesitan nuestros soldados nada que acucie y estimule su valor, tan heroica y repetidamente probado, pero al hojear sus páginas y revivir roda la grandeza de Bailén, Gerona, el dos de Mayo y los sitios de Zaragoza tiene que servir de consuelo a sus sufrimientos saber que, nuevos héroes de otra guerra de independencia, la historia recoge y glorifica sus dolores", Ibidem

65 Ibidem 
En una nota manuscrita ${ }^{66}$, Javierre se permite realizar una serie de aclaraciones y consideraciones sobre la operatividad del Servicio. En primer lugar, señala que por las especiales características de los hospitales del distrito universitario, "de primera línea", los heridos son evacuados en cuanto están en condiciones de soportar el viaje, quedando en los centros aquellos que por su gravedad o el carácter especial de sus lesiones "no pueden exponerse a él". Este hecho impide que se organicen, como parece ser su intención, conferencias en ellos, ya que es imposible que se reúnan en una sala al permanecer todos en la cama. Sí que se muestra partidaria de utilizar la emisora de radio para difundir tales disertaciones, con la colaboración de la Delegación de Prensa y Propaganda.

En segundo lugar, expresa la enorme dificultad que supone coordinar la totalidad de los centros hospitalarios bajo su jurisdicción, no sólo por su elevado número ("más de 20 hospitales fuera de Zaragoza"), sino sobre todo por la carencia de medios para trasladarse a las diferentes localidades donde se asientan, "a pesar de haberlo solicitado insistentemente". Los objetivos de controlar y dirigir la lectura en los distintos centros y hospitales y de vigilar el estricto cumplimiento de las normas por las personas designadas, quedaban seriamente condicionados por esta limitación de personal y medios. ${ }^{67}$

La precariedad llega hasta el punto de que la máquina de escribir que utilizaban, prestada temporalmente por la sede jaquesa de la universidad, fue reclamada por la misma, lo que impidió la realización de la copia del catálogo que se repartía con cada uno de los lotes remitidos a los hospitales.

Pero lo más preocupante es la inexistencia de financiación ministerial del Servicio, que obligaba incluso a sufragar con el dinero particular de los encargados del Servicio gastos derivados de su gestión, como se encarga de recalcar la propia Javierre. El único aporte económico proviene de la Delegación Militar de Prensa y Propaganda. ${ }^{68}$

La relación epistolar entre Lasso de la Vega y Aurea Javierre experimentará un incremento, tanto en número como en variedad y profundidad de los asuntos tratados, tras el ascenso del primero a la Jefatura del Servicio de Archivos, Bibliotecas y Museos, incluso fuera de los cauces meramente oficiales. ${ }^{69}$

La complicidad entre ambos generará un trasvase constante de información que trasciende los cometidos del Servicio de Lecturas, y que impacta directamente sobre el proceso de reorganización del CFABA en el que estaba sumido Lasso.

Uno de los aspectos que más preocupaba a Lasso de la Vega era el desconocimiento de la situación de los archivos en las zonas controladas por el gobierno republicano, sobre todo en Cataluña, Madrid y Valencia. A ello debemos unir la convicción del escaso interés que las autoridades nacionales prestaban al

ABUZ. Nota manuscrita de Aurea Javierre sobre el alcance y operatividad del Servicio de Lecturas (s.f.). Ibidem

que "ha hecho en todo momento cuanto le ha sido posible para facilitar esta labor" Ibidem

69 En una carta fechada en Vitoria Lasso manifiesta su pesar a Javierre por "el asesinato de sus familiares oscenses a manos de esos bárbaros marxistas". ABHMV. Fondo Lasso de la Vega. Carta de Lasso de la Vega a Aurea Javierre ofreciendo su pésame por el asesinato de sus familiares oscenses. Vitoria, 22 de abril de 1938. 
patrimonio bibliográfico y documental, contrapuesto al manifestado por las obras artísticas y monumentales, más susceptibles de ser utilizadas como elementos de propaganda. Ambas circunstancias motivaron que tanto Lasso como el Inspector de Archivos Gómez del Campillo procuraran adquirir todo tipo de elementos de juicio que justificaran la necesidad de no relegar a un segundo plano una vertiente cultural de tanta transcendencia como la archivística.

El conocimiento de la situación de los fondos documentales y la experiencia que había adquirido durante su etapa en el Archivo de la Corona de Aragón indujeron a Lasso a solicitar a Javierre la redacción de un informe sobre los archivos, bibliotecas y museos catalanes. A pesar de que carecía de fuentes bibliográficas sobre el tema, confeccionó una memoria a partir de lo que recordaba y una serie de notas que conservadas de manera casual. ${ }^{70}$ En la misma carta señala además la imperiosa necesidad de obtener ejemplares de la guía de archivos de Europa publicada en 1934 como marco de autoridad fundamental desde el que acometer un estudio riguroso de los fondos archivísticos españoles. ${ }^{71} \mathrm{La}$ parte española fue encomendada a Valls Taberner ${ }^{72}$, como bien se encarga de señalar Javierre. ${ }^{73}$

En junio de 1938, Lasso encarga a Aurea Javierre la organización de una colecta de libros destinados a las bibliotecas circulantes de los buques de guerra y unidades de la flota, aprovechando la festividad de la Virgen del Carmen, patrona de la Marina. ${ }^{74}$. La captación de nuevos volúmenes resultaba extraordinariamente complicada, puesto que Zaragoza había contribuido de forma reiterada y constante en los últimos tiempos a la entrega de obras, no sólo durante la Fiesta del Libro del 23 de abril o de las sesiones de cine organizadas para recaudar libros, sino incluso a domicilio. Pese a ello, se recaudaron 3.169 volúmenes y 718,80 pesetas. ${ }^{75}$ Meses más tarde anuncia el envío de los libros organizados en 15 cajones gracias a la facturación gratuita concedida por el Gobernador Civil de Zaragoza, a lo que añadirá el resultado de una colecta extraordinaria que alcanzó las 140,55 pesetas, realizada entre los pueblos más importantes de la provincia dado el crecimiento del número de hospitales a atender. ${ }^{76}$

70 ABHMV. Fondo Lasso de la Vega. Carta de Aurea Javierre a Javier Lasso de la Vega notificándole el envío de una memoria sobre el estado de los archivos, bibliotecas y museos catalanes. Zaragoza 12 de julio de 1938

71 (Guide Internacional, 1934)

72 (VALLS TABERNER, 1934: 70-96)

73 "recuerdo que recogimos en el Archivo de la Corona de Aragón para esta guía toda la bibliografía sobre archivos españoles. Sería ahora de indudable utilidad”. ABHMV. Fondo Lasso de la Vega. Carta de Aurea Javierre a Javier Lasso de la Vega notificándole el envío de una memoria sobre el estado de los archivos, bibliotecas y museos catalanes. Zaragoza 12 de julio de 1938.

74 La propuesta sigue la orden que había firmado Sáinz Rodríguez como ministro de Cultura el 28 de junio de 1938. "Orden disponiendo que el día 16 de julio se verifique una colecta de libros con destino al personal de la Marina de Guerra". Boletín Oficial del Estado nº 5, de 5 de julio de 1938

75 "mucho si se tiene en cuenta que Zaragoza está agotada y no hay ya un libro". ABHMV. Fondo Lasso de la Vega. Carta de Lasso de la Vega a Aurea Javierre sobre la recaudación durante la Fiesta del Libro en Zaragoza. Vitoria 1 de agosto de 1938. Los libros fueron depositados en la BUZ y del dinero se hizo cargo Gómez del Campillo, inspector general de archivos y bibliotecas. Oficio de 2 de agosto de 1938 de Aurea Javierre a Lasso de la Vega.

76 ABHMV. Fondo Lasso de la Vega. Carta de Aurea Javierre a Lasso de la Vega anunciando el envío de 15 cajas de libros procedentes de la colecta de la Fiesta del Libro en Zaragoza. Zaragoza 19 de noviembre de 1938. 
Lejos del triunfalismo de los informes y las memorias elaboradas por los encargados del Servicio, en los que el verbo artificioso enmascara la realidad, la percepción de Lasso era mucho más crítica y escéptica. En septiembre de 1938 envía una carta a Javierre en la que contempla la posibilidad de suspender el proyecto tal y como estaba estructurado, y sustituirlo por el modelo alemán basado en una serie de bibliotecas circulantes centralizadas y coordinadas desde las plazas de mando. ${ }^{77}$ Constata además el impacto que la asfixiante carencia de medios tiene sobre el ya precario apoyo de las autoridades, y apunta a la posibilidad de convertir a Aurea Javierre en la hipotética directora nacional del Servicio si logra consolidar sus reformas. ${ }^{78}$

\subsection{Lasso de la vega y el servicio de lectura al soldado de Zaragoza}

En el año 1938 las estructuras administrativas del bando nacional experimentan un significativo cambio. Ya articuladas en torno a carteras ministeriales, y desvestidas de su halo de provisionalidad puramente "campamental", como expresaría Serrano Suñer para definir este primer período de Junta Técnica, comienzan a definir más claramente los marcos de actuación y las coordenadas sobre las que se va a cimentar el Nuevo Estado, consciente de su inminente victoria militar.

El binomio Sáinz Rodríguez-Lasso de la Vega se torna fundamental para explicar el enorme dinamismo y despliegue legislativo experimentado en el ámbito de los archivos, bibliotecas y museos a partir de marzo de 1938. La obsesión normativa alcanza todos los ámbitos, y en ese contexto surgen precisamente las Instrucciones para el Servicio de Lectura del Soldado ${ }^{79}$, un pormenorizado y exhaustivo Reglamento que supera con creces la iniciativa primigenia y apresurada de Artigas, ya relegado a un segundo plano. ${ }^{80}$

El documento incluye todos los aspectos que pueden favorecer el desarrollo del Servicio, y es el resultado de la experiencia de Lasso de la Vega y sus conocimientos sobre biblioterapia. Resultan de extraordinario interés las consideraciones previas que le acompañan. Lasso interpreta al bibliotecario desde una vertiente terapéutica, derivado de su consideración como intermediario entre los libros y el lector, de la misma forma que el médico sirve de puente entre el enfermo y la dispensa de medicamentos en la farmacia. ${ }^{81}$ Este símil le permite

77 “... de no tener organizado el servicio en debida forma distribuir los libros a voleo es tirarlos sin resultado práctico". ABHMV. Fondo Lasso de la Vega. Carta de Lasso de la Vega a Aurea Javierre sobre la necesidad de modificar el modelo organizativo del Servicio de Lectura del Soldado. Vitoria 16 de septiembre de 1938.

78 ABHMV. Fondo Lasso de la Vega. Carta de Lasso de la Vega a Aurea Javierre sobre la posibilidad de nombrarla directora nacional del Servicio de lecturas del Soldado. Vitoria 22 de noviembre de 1938.

79 ABUZ. LASSO DE LA VEGA, Javier. Instrucciones para el Servicio de Lecturas para el Soldado en los Frentes y Hospitales. Vitoria, 1938.

80 Lasso envió dos oficios a Zaragoza a los que adjuntó las citadas instrucciones. El primero iba dirigido a Aure Javierre como Jefe del Servicio de Lecturas para el Soldado en los Frentes y Hospitales. Vitoria, 12 de mayo de 1938. El segundo tenía como destinatario a Miguel Artigas en su calidad de Inspector General de Bibliotecas. ABUZ. Oficio de Javier Lasso de la Vega a Aurea Javierre y Oficio de Javier Lasso de la Vega a Miguel Artigas notificando el envío de las Instrucciones para el Servicio de Lecturas para el Soldado. Vitoria, 18 de mayo de 1938

81 Ibidem 
concluir que mientras los galenos atienden y curan el cuerpo, los bibliotecarios pueden remediar el espíritu, sobre todo aquellos de los que depende el servicio en los hospitales. ${ }^{82}$

El sustento teórico de sus afirmaciones proviene en parte del grupo de bibliotecarios y médicos internistas americanos que en la década de los años 30 comenzó a interesarse por las posibilidades paliativas que ofrecían los libros, destacando específicamente las investigaciones y conclusiones de Kent Clarke, médico del Departamento de Psiquiatría de la Universidad de Rochester. ${ }^{83}$

En opinión de Lasso de la Vega, Clarke consideraba fundamental crear un ambiente de optimismo en el paciente con el fin de mejorar las posibilidades de éxito de los tratamientos médicos. Los libros, según él, conformaban una terapia muy útil para evitar o paliar los momentos de depresión que acompañan a los enfermos. ${ }^{84}$

Estima Lasso que los bibliotecarios deben supeditar y abandonar la tentación de mejorar espiritual, moral, política y profesionalmente al hospitalizado a la de procurarle un estado de evasión y entretenimiento capaz de apartar su imaginación de los dolores causados por su convalecencia. Esa labor fundamentalmente recreativa de la lectura estará condicionada además por el objetivo real, que no es otro que colaborar con el médico para facilitar la curación del enfermo con todos los instrumentos a su alcance.

Pero ello no es óbice para afianzar su faceta mediadora y depuradora. Conocer el valor terapéutico del libro permitirá al bibliotecario elegir de manera adecuada las obras que mejor se adapten a las condiciones morales e intelectuales del enfermo, y también a su situación anímica y estado físico. Estas premisas tienen como finalidad, y en orden de prelación, recrear, consolar, formar y cooperar a su mejoramiento profesional y científico.

Resultan preferibles las lecturas amenas y ligeras, dispensadas a modo de sedantes, a aquellas que supondrían un esfuerzo intelectual incompatible con el estado de salud tanto mental como físico de los enfermos. ${ }^{85}$ Las más eficaces son

82 Recuerda que el nombre de la primera biblioteca fundada en Egipto puede traducirse al español como remedio del alma. Ibidem

83 La inclusión de la literatura como parte del tratamiento de los pacientes tuvo una considerable fortuna bibliográfica en Estados Unidos en esa década. Resultan muy significativos los trabajos del ya mencionado CLARKE "Books for the Convalescent", Library Journal, December 1, 1937, pp. 893-95. Pero también SHOREY, Katherine. "The Hospital Library". Library Journal, December 1, 1937, pp. 895-97; Zoe WRIGHT, bibliotecaria del Hospital Universitario de la Universidad de Iowa, escribió "Bibliotherapy in a Children's Hospital”, Library Journal, December 1, 1937, pp. 898-900 A finales de los años 30 incluso comenzó a barajarse la posibilidad de considerar la biblioterapia como una disciplina científica, a través de artículos como el de BRYAN, Alice I. “Can There Be a Science of Bibliotherapy?”. Library Journal, October 15, 1939, pp. 773-76. (KUEHL HARBAUGH, 1984)

84 "Afirma el Dr. Clarke que la medicina científica moderna reconoce que todo enfermo sufre una depresión mental durante su enfermedad y que todo tratamiento médico debe llevar consigo la aplicación de toda clase de factores que puedan contribuir a crear un estado emocional de optimismo. Durante la enfermedad, el temor y la ansiedad que provoca la dolencia la perspectiva de un futuro incierto, el eco que los sufrimientos hallan en la economía personal del paciente, las molestias físicas y largas horas de aislamiento fomentan largas instrospecciones que combinadas dan origen a un estado psicológico deprimente. La mejor medicina para combatir estos estados son los libros.” ABUZ. LASSO DE LA VEGA, Javier. Instrucciones para el Servicio de Lecturas para el Soldado en los Frentes y Hospitales. Vitoria, 1938.

85 "Sería vano intento el pretender desplegar una labor cultural con el paciente. Salvo en casos raros en que esto lo reclamase. Y aún así habría que tener en cuenta que al enfermo podía pedir libros de estudio más o menos 
aquellas que logran excitar la curiosidad y absorber la imaginación de los lectores, puesto que de esa forma esquivan con mayores posibilidades los rigores y las penurias de su enfermedad. Los géneros preferidos por tanto serán las novelas policíacas, las históricas y de aventuras, los libros de viajes y las biografías.

En cuanto al catálogo de obras que deben rechazarse, el texto señala en primer lugar todas las que puedan atentar contra los principios nacionalcatólicos imperantes o que inciten a la crispación y la turbación interior. ${ }^{86}$ Incluye también, por razones obvias, los libros de medicina que guarden relación directa con sus dolencias, y los de contenido deprimente que contribuyan a empeorar su ya debilitado estado de ánimo ${ }^{87}$. Y por último incorpora los libros de humor, puesto que "se tornan muchas veces irritantes para el enfermo". ${ }^{88}$

Para realizar con éxito esta función selectiva, el encargado del servicio debe previamente realizar una suerte de entrevista de referencia a los posibles lectores para conocer con exactitud los "gustos, aficiones y conceptos del mundo moral y espiritual que nos rodea". Esta conversación sitúa al bibliotecario en inmejorable camino para "recetar" con eficacia la segunda lectura, y lo prepara para saber discernir bien en casos similares.

Respecto a las características específicas del servicio, en primer lugar la dirección del centro ha de distinguir entre enfermo y herido, ya que éste último es un hombre sano, que puede realizar una lectura formativa, instructiva y recreativa a la vez, frente al segundo, más determinado y condicionado por su dolencia. Al mismo tiempo, se dispone que las lecturas en las salas de enfermos mentales y epilépticos han de someterse forzosamente al consejo del médico encargado de ella.

Los libros deberían entregarse a sus destinatarios envueltos a ser posible en forros de papel de clase ínfima, incluyendo las leyendas, condiciones y reglas de lectura señaladas en las instrucciones. Como medida de desinfección, se estima que la mejor opción es someter al libro al sol y a la ventilación natural.

Los encargados de la sala llevarán un cuaderno de anotaciones con el nombre del hospital, en el que consignará distintamente en página separada para cada lector hospitalizado una plantilla. ${ }^{89}$ Cada hospital dispondrá de un depósito de libros con el conjunto de obras seleccionadas para la lectura, y a ser posible con algunos más de consulta como atlas, diccionarios, geografías, gramáticas, historia ...

Dentro del organigrama del Hospital, al frente del servicio se colocará una persona responsable de la gestión del mismo, acompañada, siempre que las

serios guiado por un falso aprecio de la actual condición de sus facultades o bien llevado por un prurito vanidoso de impresionar ya al bibliotecario ya a los compañeros de hospital" Ibidem

86 "Deben abolirse en los hospitales aparte de las lecturas de índole inmoral, sexual, antirreligiosa o de política contraria al régimen, todas aquellas otras de desenlace fatalista o que anuncia cualquier rebeldía íntima" Ibidem

87 Lasso pone como ejemplo cualquier novela de querellas familiares en la que "el protagonista fuese un ser digno de lástima, llevaríales por un lado a sentir como suyas las desgracias del protagonista, uniéndose a los pesares reales producidos por la enfermedad, los imaginados del héroe de la novela" Ibidem

88 Ibidem

${ }^{89}$ Los campos de que consta la plantilla son los siguientes: Sala; $\mathrm{n}^{\mathrm{o}}$ de cama; Nombre y naturaleza del hospitalizado; Títulos y profesión; ¿Qué libro le ha gustado más?; ¿Cuáles son sus aficiones literarias; ¿Qué películas le gustaron más?; Tipo de dolencia; y Lectura solicitada, Ibidem 
circunstancias lo permitan, de otra más especializada y que asumirá la tarea de aconsejar o establecer las guías de lectura que considere. Para subsanar todos los problemas que se planteen se crea el Consejo de Lectura, formado por todos los consejeros de los hospitales de una población.

Se trata por tanto de utilizar el bagaje profesional y la capacidad técnica de los Facultativos del CFABA como aportación al triunfo del bando nacional a través del suministro de lecturas dirigidas a los soldados heridos, pero también de reivindicar su importancia corporativa como mediadores necesarios entre la cultura y la población, consciente Lasso de la escasa consideración de la que gozaban.

El texto considera importantes dos cuestiones que no deben soslayarse, muestra del escaso margen de maniobra del que gozaban los bibliotecarios con respecto a la Dirección de los hospitales:

1.- Solamente se podrán dar libros a aquellos enfermos y organizar lecturas en alta voz en aquellas salas de hospitales que fuesen autorizados por la Dirección.

2.- A los pacientes de enfermedades contagiosas no se les facilitarán libros de bibliotecas públicas ni circulantes, pero se les dotará con una colección fija de obras selectas y variadas cuando el carácter de la enfermedad lo permita, y si la Dirección facultativa lo autorizase por escrito.

El Reglamento incorpora los siguientes contenidos:

\section{a) Propaganda}

Uno de los requisitos primordiales e imprescindibles para asentar el proyecto consistía en obtener ayuda económica, libros y otros recursos necesarios para su evolución. Para ello, la norma apuesta por desarrollar una campaña multicanal con la utilización de todos los medios de propaganda disponibles: prensa, carteles, pasquines, lecturas y conferencias y radio. Dispone una estrategia que aumente el grado de penetración y apoyo al Servicio, y suscite el entusiasmo difundiendo anécdotas que inciten y conmuevan a la población. ${ }^{90}$

Unido a ello, solicita el apoyo de las librerías comerciales mediante el donativo gratuito de sus fondos editoriales y su posterior envío a precio de coste. El estímulo en este caso procede de la exposición pública de aquellas que acepten las propuestas de participación.

Otra acción se dirigía a la organización de eventos destinados a recoger libros, en los cuales tendrán una participación directa las Delegaciones de Prensa y Propaganda del Estado y Falange Española, encargadas de la edición de carteles y pasquines destinados al efecto. Con ello se pretendía no sólo implicar a las

90 "la del soldado que en vez de pedir novelas reclama cuentos para poder contarlos a su vez a sus hijos cuando regrese del frente. El conductor de automóviles que solicita libros de mecánica para ser más eficaz en su profesión cuando abandone el hospital. El gitano que inquiere por el pleito de Jesús, ése que mataron los judíos. El que no pide sino una cartilla para aprender a leer durante los descanso de la guardia en las trincheras, o para enseñárselo al compañero analfabeto en la sala del hospital" Ibidem 
autoridades sublevadas en la dinámica del Servicio, sino atraer al mayor porcentaje de población posible, consciente del enorme poder e influencia del Falange en la vida cotidiana de la retaguardia. El Reglamento concreta tres actividades:

- Día del libro del soldado o semana del libro del soldado

- Cuestaciones para la compra de libros nuevos, y

- Programas especiales de propaganda con destino a la América española

Otras medidas se encaminaban a la publicación y venta de fotografías de las instalaciones del servicio de lectura en los frentes y hospitales, cuya recaudación iría íntegramente a cubrir las necesidades del mismo; y la organización de conferencias o lecturas por personalidades competentes que tuvieran como condición de acceso la entrega de un libro.

\section{b) El proceso técnico}

La labor técnica estaba adaptada a la propia idiosincrasia del Servicio. Con un sentido eminentemente práctico y utilitarista, no se pretendía generar un catálogo bibliográfico en sentido estricto, sino disponer de una herramienta de gestión que permitiera, en la medida de lo posible, controlar las remesas y entregas de los libros y mejorar la agilidad en los trámites de recepción y devolución.

\section{b.1.) Recepción de libros}

Tras su entrega o recogida, se procedería al registro de los mismos, en el que se incluiría el título, el nombre del donante y su dirección.

La admisión de los libros será responsabilidad del personal competente nombrado para tal efecto, y estará determinada por su adecuación al Servicio y/o por su contenido. Aquellos que no se consideraran pertinentes se entregarían a la Biblioteca Pública Provincial del Estado para su custodia, tal y como se había señalado desde la jefatura de Archivos, Bibliotecas y Museos.

En segundo lugar se procederá al sellado de las obras admitidas con la leyenda "Lecturas para el Soldado en los Frentes y Hospitales" en varias de sus páginas. Incorporará además otros sellos con frases alusivas a la necesidad a la conservación del libro en buen estado.

\section{b.2.) Clasificación y catalogación}

Tras el registro, los libros pasarán a la fase de clasificación por materias, y posteriormente se agruparán dentro de éstas siguiendo un orden alfabético. Los libros se dispondrán de esta forma en las estanterías. Una vez ordenados, se sacarán listas con diez o veinte títulos que, a través de máquinas multicopistas, se enviarán a los frentes y hospitales a modo de índices para que en los destinos conozcan los contenidos.

\section{c) Expediciones}

Para el envío de los libros se utilizaría el Servicio de Correos, conformando paquetes postales dentro de los límites de peso permitidos por las oficinas de este 
organismo. Éstos irán sellados con un timbre indicador del Servicio para el que se destinan, previo acuerdo y consenso con el Jefe Local de Correos. ${ }^{91}$

Constata el reglamento la necesidad de cursar instrucciones breves, concretas y claras a las personas encargadas de la recepción y custodia de los paquetes de libros en los frentes de batalla. Debían incluir aspectos relativos al cuidado del libro; el fomento de la lectura en voz alta a los analfabetos que mostrasen su deseo de escucharla; y por último, a la propia circulación del mismo. En las guardas del libro, y a modo de ficha de lectura y control, se fijará un papel donde se irán inscribiendo los nombres de todos los lectores que lo utilicen, correspondiendo al último que figure la responsabilidad de su buen uso y devolución. En el caso de que los libros hubieran sido ya leídos por parte de todos los integrantes del destacamento o grupo, se procederá a su empaquetado y reingreso a la oficina Central del Servicio. También pueden recomendar su envío a otra compañía o destacamento adjuntando el nombre del capitán al mando.

\section{d) Servicios especiales}

Quizá el aspecto más llamativo y sorprendente proceda del intento de organizar tanto un servicio de peticiones especializadas como, y sobre todo, de referencias o consultas bibliográficas. En el primer caso, aquellos que mostrasen su interés por utilizarlo, debían dirigirse por medios postales al Jefe Provincial de Lecturas para el Soldado especificando el libro o los libros que necesitaran, independientemente de su contenido. La Biblioteca intentaría mandar la obra solicitada con arreglo a las normas del reglamento de Préstamo citadas.

Con respecto al servicio de referencia, podrían solicitar la resolución de consultas bibliográficas, siendo potestad del encargado, o bien responder personalmente a la petición o derivarla a otra persona con mayor competencia para hacerlo.

También se intentaba dinamizar un programa de lecturas adaptado tanto para aquellos que no tuviesen capacidad para leer, bien por causas físicas (ciegos o incapacitados) o culturales (analfabetos). En su planificación, siempre dirigida y controlada, procurando sobre todo exaltar el ánimo y las ansias de combate, deberían atender: $1^{\circ}$ noticias de actualidad más relevantes; $2^{\circ}$ hechos de valor nacional más destacados, como por ejemplo la apertura de nuevas escuelas, construcción de casas para obreros, botaduras de buques de guerra, etc; $3^{\circ}$ efemérides históricas de la guerra, batallas ganadas, biografía nacional, descubrimientos científicos, conmemoración de la revolución actual, etc; $4^{\circ}$ lectura de alguna composición o trozo selecto de algún autor clásico; y $5^{\circ}$ lectura de novelas de aventuras o del carácter que se considere más adecuado.

Dispone un espacio para realizar programas cíclicos temáticos, con un objetivo instructivo predeterminado y adaptado. Como primera medida señala difundir entre los soldados un listado de temas posibles para que elijan los que consideren más adecuados o atractivos; tras conocer el número de los interesados, se concretarían

\footnotetext{
${ }^{91}$ El modelo de las etiquetas también estaba determinado, y el membrete contenía estos campos: Lecturas para el soldado en el frente y hospitales, Delegación de ...., Envío de ...., La correspondencia se dirigirá al Jefe del Servicio en la Biblioteca de ...
} 
atendiendo a diversos parámetros: la capacidad y preparación literaria del lector o lectores, el tiempo de que se puede disponer para su desarrollo, y la intencionalidad del lector. No sería lo mismo, justifica Lasso, afrontar un plan de lecturas para aquellos que pretendan conocer las obras más representativas de la literatura romántica, que para quienes establezcan como objetivo preparar su grado de Licenciado en la Facultad de Filosofía y Letras. ${ }^{92}$

\subsection{Los medios de captación de fondos}

\subsubsection{Las donaciones}

La estrategia para captar obras y dinero en metálico con el que mejorar y ampliar el Servicio se estructuró mediante tres tipos de intervenciones: la entrega sin límites temporales en la propia sede de la Biblioteca de la Universidad de Zaragoza u otras instituciones; la organización de sesiones cinematográficas específicas en las que la entrada se obtenía mediante la entrega de un libro y, por último, el aprovechamiento de determinadas celebraciones, básicamente la Fiesta de la Raza y la Fiesta del Libro, para estimular la donación de las obras.

Los primeros registros de los donantes particulares comienzan el 1 de junio de 1937 y se desarrollan durante todo el verano, hasta que prácticamente desaparecen, relegados por la mayor efectividad y control de las sesiones cinematográficas. La nómina de títulos retirados por sus contenidos, tildados de "pornográficos", entre las entregadas por las personas de forma individualizada en la biblioteca, no es muy numerosa. ${ }^{93}$

La segunda de las vías de captación de fondos surgió claramente influenciada por la estrategia diseñada por Lasso de la Vega en Sevilla. La entrega de una obra garantizaba el acceso a las sesiones cinematográficas programadas, lo que supuso un enorme éxito y el aumento de los fondos disponibles para el Servicio. Sin embargo, con este procedimiento creció el número de obras censuradas, quizá debido a que la inmediatez de su entrega hacía más complicado el control de las mismas.

La carencia de homogeneidad en los criterios y tratamiento de las obras consideradas nocivas producía numerosas situaciones paradójicas, como el hecho de que se admitieran las mismas obras que en otras ocasiones se retiraban sin contemplaciones. Buena parte de ellas formaban parte de una colección de novelas cortas, La novela de hoy, heterogéneas en cuanto a sus contenidos, pero con algún relato cercano a la literatura erótica y presidido por un componente naturalista en la línea de Zola.

92 Ibidem

93 A Sixto Casamayor se le censuran El milagro del Padre Malaquías de Howard Marshall y Las fronteras de la pasión de Alberto Insúa. A José Robles: La Venus miente de Rafael López de Haro. A Carolina Miguel: La vida amorosa de Luis XIV escrita por Loiuis Bertrand, y La Vida amorosa de Madame Pompadour de Marcelle Tinayre. A la Sra. Gascón de Arpal: Publicanos y pecadores de M.E. Bradon; La hija abandonada de Elaine Coffman; y las obras de Carolina Invernizio El seductor, La lucha por el amor, Los traumas del adulterio, Misterios de las buhardillas y La revancha del macho y a Vicente Barra diversas novelas de la misma escritora italiana: La novia del bersagliere, Los siete cabellos de oro del Hada Gusmara, El marido de la muerta y La pecadora. 
Existe otro grupo de obras entregadas por los asistentes que no pasaron a engrosar el fondo bibliográfico del Servicio de Lecturas. El registro de las mismas sigue un criterio cronológico que se completa con la referencia al lugar donde se celebra cada una de las sesiones. La mayoría de ellas tuvieron la consideración de "pornográficas", si bien hay algunas de contenido más político. ${ }^{94}$

En la tabla siguiente se reflejan las obras recogidas y el número de ellas que fueron retiradas y/o censuradas por los encargados de su recepción. Gracias a ella se constata que el porcentaje total de obras retiradas fue muy pequeño, el 3,9\%.

Tabla 3.- Volúmenes recogidos y censurados en las sesiones cinematográficas

\begin{tabular}{|l|c|c|c|}
\hline \multicolumn{1}{|c|}{ Sesión } & Obras & Retiradas & $\mathbf{\%}$ \\
\hline Cine Victoria (22/10/1937) & 313 & 0 & 0 \\
\hline Cine Monumental (26/10/1937) & 210 & 0 & 0 \\
\hline Cine Frontón-Cinema (29/10/1937) & 551 & 6 & 1,1 \\
\hline Cine Monumental (31/10/1937) & 315 & 14 & 4,4 \\
\hline Cine Victoria (04/11/1937) & 147 & 6 & 4,1 \\
\hline Monumental (04/11/1937) & 198 & 6 & 3,0 \\
\hline Frontón Cinema (11/11/1937) & 424 & 18 & 4,2 \\
\hline Cine Monumental (15/11/1937) & 214 & 2 & 0,9 \\
\hline Cine Victoria (19/11/1937) & 357 & 13 & 3,6 \\
\hline Cine Monumental (21/11/1937) & 167 & 18 & 10,8 \\
\hline Frontón Cinema (25/11/1937) & 400 & 10 & 2,5 \\
\hline Cines Monumental y Victoria (28/11/1937 y & 467 & 59 & 12,6 \\
\hline C2/12/1937) & & & \\
\hline Cine Monumental (05/12/1937 y 08/12/1937) & 387 & 46 & 11,9 \\
\hline Frontón Cinema (09/12/1937) & 162 & 1 & 0,6 \\
\hline Cine Monumental (12/12/1937) & 132 & 0 & 0 \\
\hline Sin especificar (16/12/1937) & 257 & 0 & 0 \\
\hline Sin especificar (19/12/1937) & 107 & 0 & 0 \\
\hline Sin especificar (23/12/1937) & 205 & 2 & 1,0 \\
\hline Sin especificar & 187 & 0 & 0 \\
\hline TOTAL & $\mathbf{5 . 2 0 0}$ & $\mathbf{2 0 1}$ & $\mathbf{3 , 9}$ \\
\hline
\end{tabular}

94 Miguel Artigas en una carta dirigida a Lasso de la Vega, ofrece sus opiniones con respecto a las listas de los libros enviados a los cuarteles por el Servicio, y es consciente de que muchos de ellos, si no pornográficos, sin son al menos inmorales, aunque matiza que esa concepción depende del lector: "las he leído [las listas] y en algunas eh puesto consigna al margen. Son pocas. Se trata de libros si no francamente pornográficos si libros inmorales. Claro es que leyendo esto muchos de los lectores que hayan de usarlos y la intención que lleven al leerlos. No creo que se deban destruir ninguno; pero si tal vez apartarlos. En general proceden de bibliotecas ya expurgadas". ABHMV. Fondo Lasso de la Vega Carta de Miguel Artigas a Lasso de la Vega sobre libros inmorales. 11 de diciembre de 1938. 
A partir del año 1938 se observa una relajación en el nivel de exigencia censor, como bien muestra la práctica inexistencia de obras retiradas. Tal circunstancia puede probablemente explicarse por el agotamiento de las donaciones, como pone de manifiesto Javierre en sus comunicaciones con Lasso y Campillo.

\subsection{Las colectas extraordinarias}

La mayor parte de los libros y revistas recibidos en la Biblioteca de la Universidad de Zaragoza procedían de acontecimientos y celebraciones concretas que se acompañaban de una recogida masiva de obras. Los dos más significadas eran la Fiesta de la Raza el 12 de octubre, y la Fiesta del Libro el 23 de abril, debido a las evidentes connotaciones simbólicas de ambas fechas, revestidas siempre de exaltación patriótica y religiosa, y la búsqueda de argumentos ideológicos en el pasado imperial español.

La planificación de los actos obedecía a una estructura preconcebida, diseñada desde la Jefatura de Archivos, Bibliotecas y Museos, en la que se mezclaba la colocación de mesas petitorias en lugares estratégicos de la ciudad con discursos y conferencias que contribuían a realzar su solemnidad institucional.

Javierre ${ }^{95}$, muestra cómo se cumplió estrictamente con lo señalado en la orden de 11 de abril del mismo año dictada por el Ministerio de Educación Nacional ${ }^{96}$, reforzado por la nota enviada por Lasso de la Vega en su condición de Jefe de los Servicios de Archivos, Bibliotecas y Museos. ${ }^{97}$ Bajo la supervisión y organización del Servicio de Lecturas para el Soldado, en primer lugar se solicitó el apoyo de todas las instituciones: autoridades civiles y militares, la Delegación de Cultura de Falange y las Delegaciones, tanto civil como militar, de Prensa y Propaganda. Como medio de difusión, ocho días antes de la misma todos los periódicos de Zaragoza y la emisora de radio, en sus tres presencias diarias, publicaron anuncios rogando la colaboración de los ciudadanos ${ }^{98}$.

95 ABUZ. JAVIERRE, Aurea. Memoria de los actos celebrados en Zaragoza con motivo de la Fiesta del Libro. Zaragoza, 23 de abril de 1938.

96 "Orden dictando reglas sobre la celebración de la Fiesta del Libro". Boletín Oficial del Estado n 541,15 de abril de 1938. La orden, firmada por Sáinz Rodríguez, establecía que todas las universidades y centros de enseñanza en general celebraría sesiones solemnes de ensalzamiento del libro, y que todas las instituciones públicas dedicarán un mínimo del $1 \%$ de las subvenciones recibidas para la compra y reparto de libros de autores clásicos españoles y publicaciones editadas por el Servicio de Propaganda del estado, y los ayuntamientos una cuantía del medio al 3 por mil de su Presupuesto a dicho reparto, y creación o acrecentamiento de bibliotecas populares. Además, éstos concederán permisos gratuitos para la instalación de puestos de venta de libros en la vía pública, que venderán los mismos con un descuento del 10\%

97 ABUZ. Servicio de Lecturas del Soldado. Oficio de Lasso de la Vega dirigido al Jefe del Servicio de Lecturas para el Soldado en Frentes y Bibliotecas con las directrices a seguir en la Fiesta del Libro. Vitoria 11 de abril de 1938.

98 "La celebración de la Fiesta del Libro va a tener este año en la España Nacional una modalidad nueva, a tono con el momento de guerra, que la hace sumamente simpática. Los soldados que pelean por Dios y por España en los frentes de batalla, y los que contemplan el lento desfile de las horas en las salas de los hospitales de guerra, necesitan libros que, a la vez que levanten su nivel intelectual, proporcionen a su espíritu solaz y esparcimiento. A este fin se colocarán mesas petitorias en las que se recogerán cuan tos libros se donen para la Biblioteca del Soldado. Esperamos que los zaragozanos, conscientes siempre de sus deberes, se esmerarán en subvenir a esta necesidad de la guerra, regalando libros de su biblioteca, por modestos que sean, siempre que 
Al mismo tiempo, se enviaron circulares a autoridades, corporaciones y personas relevantes invitándoles a entregar donativos de libros en los que, como homenaje a los soldados, añadiesen dedicatorias alusivas.

El mismo día 23, a las 10 de la mañana, quedaron instaladas mesas petitorias ubicadas en los más céntricos lugares de la ciudad, adornadas con la bandera española y con plantas y flores ofrecidas por el Ayuntamiento. Cada una de ellas iba acompañada de un cartel con el lema Lectura para el Soldado. Pedimos un libro para los combatientes.

La Presidencia individual fue asumida por las esposas de las autoridades, que se distribuyeron entre los lugares más emblemáticos de la ciudad: Plaza de Aragón, Paseo de la Independencia, Plaza de España, la Audiencia, la Plaza del Pilar, la calle del Coso, la calle Don Jaime, el Paseo Sagasta y la Plaza de Sas. ${ }^{99}$

Figuraban además representaciones de los centros docentes de la localidad, de la Sección Femenina de Falange, del SEU y Flechas. En todas ellas el sitio de honor fue ocupado por un soldado herido, "cuya presencia fue acogida con gran simpatía por el público". 100

Por acuerdo con la Delegación Militar de Prensa y Propaganda, no se admitieron donativos en metálico. ${ }^{101}$ La colecta arrojó un resultado de 9.324 volúmenes, a los que debemos añadir un donativo de 50 pesetas del Banco de Aragón y 46,25 pesetas y 47 libros procedentes de la alcaldía de Cariñena.

La segunda parte de la festividad incorporaba una vertiente más "cultural", protagonizada por conferencias y actos literarios. Javierre refleja que debido a la imposibilidad de celebrar encuentros literarios individualizados para cada uno de los cuarenta hospitales que estaban bajo la jurisdicción del distrito zaragozano, y con la aquiescencia y colaboración del comandante Pardo, se decidió retransmitir a todos ellos una velada literaria desde los estudios de la emisora local de Zaragoza, compuesta de un programa que integraba:

su contenido armonice con los santos ideales de la actual Cruzada, en las mesas petitorias instaladas en diversos lugares estratégicos de la población”. "La Fiesta del Libro", El Noticiero, 22 de abril de 1938.

99 El reparto y la adjudicación de las zonas fue el siguiente:

1. Plaza de Aragón: Señora del General Jefe de la $5^{\text {a }}$ región Militar, general Francisco Rañoy Carvajal

2.- Paseo de la Independencia: Señora del Inspector General de Archivos, Miguel Gómez del Campillo

3.- Plaza de España: Señora del Presidente de la Diputación, Miguel Allué Salvador que ostentaba además la representación de Portugal

4.- Audiencia: Señora del Presidente de la Audiencia, Napoleón Ruiz Falcó

5.- Plaza del Pilar: Señora del Gobernador Militar de la Plaza, señor Lasala

6. Calle del Coso: Señora del Jefe Territorial de Falange, Jesús Muro Sevilla

7. Calle Don Jaime: Señora del Secretario Político del Fascio italiano

8. Paseo de Sagasta: Señora del Cónsul de Alemania

9. Coso (Calle Espartero): Delegación de Frentes y Hospitales y Auxilio Social

10. Plaza de Sas: Sindicato Español Universitario, con Ángela Rosignoli

100 Ibidem

101 Así, la Agrupación Aragonesa de Fabricantes de Jabones y Aceites quería entregar 500 pesetas, pero se le conminó a que, acompañados por Gómez del Campillo y una de las señoritas encargadas de la atención a los donantes, eligieran los más adecuados hasta alcanzar tal cantidad. Ibidem 
1.- unas palabras preliminares pronunciadas por José María Castro y Calvo, de la Subdelegación de Prensa y Propaganda. ${ }^{102}$

2.- la lectura de un capítulo del Quijote, concretamente el capítulo final De cómo Don Quijote cayó malo y del testamento que hizo y su muerte y del Soneto Imperial de Hernando de Acuña. ${ }^{103}$

3.- Palabras del Caudillo, con fragmentos de alguno de sus discursos.

4.- la poesía Romance Azul, de Rafael Duyos. ${ }^{104}$

5.- unas cuartillas redactadas por Miguel Artigas, leídas por la propia Aurea Javierre, en las que analizaba la actualidad y vigencia del Quijote y establecía cierta similitud con los objetivos perseguidos por el levantamiento armado; y por último,

6.- diversos intermedios de música española, en los que se incluyeron piezas de Falla, Albéniz y Granados.

Paralelamente, y bajo la supervisión y organización de las autoridades académicas de la Universidad de Zaragoza, tuvo lugar a las siete de la tarde una sesión de exaltación del libro en el salón de conferencias de la Facultad de Medicina, en la que intervinieron los catedráticos Salvador Minguijón, de la Facultad de Derecho, Miguel Allué Salvador, director del Instituto Goya, Luis Igualada Frías, de la Escuela Normal de Magisterio, y por último, el catedrático Pascual Galindo Romeo representando a la Facultad de Filosofía y Letras.

La entrega de los volúmenes recaudados a los hospitales se produjo algunos días después, concretamente el 2 de mayo, fecha repleta de simbolismo al tratarse de una fiesta nacional. Javierre constató el enorme esfuerzo desplegado no sólo por el personal del Servicio, sino por el resto de facultativos residentes en Zaragoza, para acometer la complejidad del proceso técnico y completar la formación de los lotes, que iba acompañado de varias copias del catálogo de materias con el fin de

102 Doctor en Medicina por la Universidad de Zaragoza en 1927 merced a su tesis Contribución al estudio de Miguel Servet y de su obra "Syruporum", publicada en 1932 por La Académica, obtuvo ese mismo año la licenciatura en Filosofía y Letras en el centro cesaraugustano. Fue ayudante y profesor auxiliar temporal en esta misma facultad, impartiendo Teoría del Conocimiento, Arte, Arqueología, Numismática, Epigrafía y Literatura Española. Se doctoró con una tesis doctoral dirigida por Ángel González Palencia titulada La Educación de príncipes en la Edad Media según las obras de D. Juan Manuel, y leída en la Sección de Historia en 1940. En 1942 gana por oposición la cátedra de Literatura en la Universidad de La Laguna, y años más tarde se asienta definitivamente en la Universidad de Barcelona. Fruto de su interés por la literatura, durante la guerra civil publicó Justas poéticas aragonesas del siglo XVII. Zaragoza: La Académica, 1937; Prosas y versos de doña Ana F. Abarca de Bolea. Zaragoza, 1938 o el prólogo a la obra de Federico Torralba Soriano Notas para la creación de un Teatro Nacional Español. Zaragoza, 1938. Sobre su periplo vital y el contexto contemporáneo zaragozano escribió unas interesantes memorias. (CASTRO Y CALVO, 1968)

103 Este poema, compuesto por su autor para conmemorar la victoria en la batalla de Lepanto frente a los turcos, fue adoptado como parte del imaginario literario falangista, y utilizado en diversas publicaciones como la revista Jerarqvia. (DUPLA, 2012: 817)

104 El poeta valenciano Rafael Duyos compuso en Romance Azul uno de los poemas escenificables más representativos de la lírica falangista y que formó parte de la antología seleccionada por él mismo Romances de la Falange, que tuvo varias ediciones (1937 y 1938 en Buenos Aires y 1939 en Valencia) 
facilitar la labor de elección a los heridos. En todos ellos figuraban un ejemplar del Quijote y otro de El muchacho español de Salaverría. ${ }^{105}$

La Fiesta del Libro del año 1939 siguió un modelo parecido ${ }^{106}$. Javierre organizó una sesión literario-musical dedicada a los heridos de los hospitales de guerra, radiada por la emisora local de Falange, ${ }^{107}$ con arreglo a un programa híbrido en el que convivían contenidos literarios con soflamas políticas relacionadas con el culto a la figura de Franco:

$1^{\circ}$ Capítulo XLII del Quijote: De los consejos que dio Don Quijote a Sancho Panza antes que fuesen a gobernar la ínsula, con otras cosas bien consideradas.

$2^{\circ}$ Canción de la España futura. ${ }^{108}$

$3^{\circ}$ Palabras del Caudillo: fragmentos de algunos de sus discursos

$4^{\circ}$ Franco, leyenda del César visionario. ${ }^{109}$

$5^{\circ}$ Discurso sobre la significación de la Fiesta del Libro, por D. Luis Alda y Tesán ${ }^{110}$

$6^{\circ}$ Intermedios musicales

Por su parte, el Patronato Provincial de Archivos, Bibliotecas y Museos coordinó la instalación de mesas petitorias situadas en los puntos neurálgicos de la ciudad, pero en mucha menor medida que el año anterior. ${ }^{11}$

La recaudación fue de 133 libros, 1.919 revistas y un número no precisado de pesetas. La intensidad de los fastos se redujo de forma considerable, debido indudablemente a que la guerra había finalizado.

Simultáneamente, los maestros de las Escuelas Nacionales de Zaragoza realizaron una colecta de libros y revistas en sus centros, que fueron enviados por la Delegación Provincial de Asistencia a Frentes y Hospitales.

105 ABUZ. JAVIERRE, Aurea. Memoria de los actos celebrados en Zaragoza con motivo de la Fiesta del Libro. Zaragoza, 23 de abril de 1938.

106 ABUZ. Servicio de Lecturas del Soldado. Oficio de Lasso de la Vega sobre la organización de la Fiesta del Libro. Vitoria, 16 de septiembre de 1938: "se sirva organizar en los Hospitales veladas literarias y musicales o simplemente lecturas sobre los temas: Cristóbal Colón, Isabel la Católica, El Caudillo, la Hispanidad, episodios heroicos de la historia de España (principalmente del Glorioso Movimiento Nacional); también se deberán hacer peticiones de libros con dicho destino por medio de la radio y de la Prensa".

107 ABUZ. Correspondencia oficial. Oficio de Aurea Javierre a Javier Lasso de la Vega notificando la celebración de una sesión literaria en la Fiesta del Libro de Zaragoza. Zaragoza 27 de abril de 1939.

108 El poeta cordobés Marcos Rafael Blanco Belmonte muestra en este poema un verbo encendido y apasionado, con el que realiza una inmersión reivindicativa del pasado imperial español y del catolicismo más beligerante como medios de contrarrestar el influjo de los enemigos de España, el "bárbaro anarquismo".

109 El poema de Federico de Urruria es sin duda alguna la composición poética laudatoria más conocida sobre la figura de Franco.

110 En realidad se trata de Jesús Alda Tesán, catedrático de Lengua y Literatura en diversos institutos aragoneses, amigo de Ramón Sijé con el que fundó la revista católica El Gallo Crisis en Orihuela en 1934.

111 En esta ocasión se dispusieron sólo tres lugares de recepción y recogida: Palacio de la Diputación, presidido por la esposa del Presidente de la Diputación Provincial; Plaza de España, presidido por la esposa del Jefe Provincial de FET y de las JONS, y por último Paseo de la Independencia, presidido por las mujeres integrantes del Servicio de Lectura. 
El Servicio continuó hasta el mes de septiembre de 1939 prácticamente reducido a la atención a los hospitales, si bien en algunos casos se enviaron libros a algunos frentes sin determinar. ${ }^{112}$

Tabla 4.- Volúmenes entregados a los Hospitales, 1938 y 1939

\begin{tabular}{|c|c|c|c|}
\hline \multicolumn{3}{|c|}{ Hospitales de Zaragoza } & \multirow[b]{2}{*}{$\%$ crecimiento } \\
\hline Hospital & 1938 & 1939 & \\
\hline Hospital del Salvador & 216 & 716 & $231,48 \%$ \\
\hline Hospital Militar & 177 & 1.493 & $88,14 \%$ \\
\hline Hospital Infecciosos & 161 & 360 & $55,28 \%$ \\
\hline Hospital de las Hermanitas de los Pobres & 154 & 154 & $0,00 \%$ \\
\hline Hospital Provincial & 152 & 820 & $81,46 \%$ \\
\hline Hospital del Sagrado Corazón & 146 & 412 & $64,56 \%$ \\
\hline Hospital Mercantil & 145 & 258 & $43,80 \%$ \\
\hline Hospital Cervantes & 140 & 357 & $60,78 \%$ \\
\hline Hospital Clínico & 135 & 396 & $65,91 \%$ \\
\hline Hospital Legionario Italiano $\mathrm{n}^{\circ} 9$ & 127 & 447 & $71,59 \%$ \\
\hline Hospital de la Enseñanza & 125 & 454 & $72,47 \%$ \\
\hline Hospitales Costa y Refugio & 123 & 749 & $83,58 \%$ \\
\hline Hospital Academia Torres & 119 & 478 & $75,10 \%$ \\
\hline Hospital Pompiliano & 105 & 283 & $62,90 \%$ \\
\hline Hospital de la Residencia de Estudiantes & 104 & 705 & $85,25 \%$ \\
\hline Hospital de las Adoratrices & 103 & 103 & $0,00 \%$ \\
\hline Hospital de la Cruz Roja & 92 & 332 & $72,29 \%$ \\
\hline Hospital Musulmán & 75 & 200 & $62,50 \%$ \\
\hline Hospital Musulmán (Corazonistas) & 75 & 60 & $-25,00 \%$ \\
\hline Hospital Musulmán (Gascón y Marín) & 75 & 100 & $25,00 \%$ \\
\hline Hospital Alemán & 57 & 57 & $0,00 \%$ \\
\hline Hospital de Ambos Mundos & 56 & 56 & $0,00 \%$ \\
\hline Hospital de la Caja de Ahorros & 55 & 183 & $69,95 \%$ \\
\hline Enfermería de Castillejos & 55 & 55 & $0,00 \%$ \\
\hline Hospital de Mutilados & 54 & 75 & $28,00 \%$ \\
\hline Hospital Villa Azul & 47 & 47 & $0,00 \%$ \\
\hline Hogar del Herido & 25 & 30 & $16,67 \%$ \\
\hline TOTAL & 2.661 & 9.380 & $71,63 \%$ \\
\hline
\end{tabular}

Durante el año 1939, el reparto de los volúmenes entre los hospitales arroja una diferencia significativa, por cuanto el final de la guerra ocasiona que únicamente se 
realice en aquel los situados en Zaragoza, y no en los ubicados en localidades limítrofes, como si ocurriera en 1938. Pese a ello, el incremento de las obras entregadas es muy notorio, con un aumento del volumen bruto porcentual del $71,63 \%$ (9.380 obras en 1939 frente a las 2.661 captadas en 1938) y algunos casos especialmente llamativos, como el Hospital Militar (88,14\%), el Hospital de la Residencia de Estudiantes $(85,25 \%)$ o los Hospitales Costa y Refugio $(83,58 \%)$. Tan sólo se observa una reducción del $25 \%$ en el Hospital Musulmán. Incluso si contabilizáramos las entregas a los hospitales limítrofes en 1938, el crecimiento alcanzaría el 54\% (4.292 en 1938 contrastadas con las 9.380 de 1939).

La cantidad entregada al Hogar del Herido en ambos años es sensiblemente inferior que el resto, puesto que al estar instalado en el antiguo Casino posee una magnífica biblioteca.

En las dependencias de la Biblioteca universitaria permaneció tras el fin de la contienda un remanente de libros, folletos y revistas, facilitados a cuarteles y cárceles siguiendo las instrucciones marcadas por el Ministerio de Educación Nacional.

Por su parte, la Fiesta de la Raza celebrada el 12 de octubre de 1938 obtuvo una recaudación de $11.316,40$ pesetas y 5.791 libros y revistas. Javierre constata de nuevo las dificultades de obtener medios de transporte, lo que entorpece las labores de cierre contable y dilata la notificación hasta varios meses después. ${ }^{113}$ Dicha cantidad fue transferida desde la cuenta corriente del Servicio a la que poseía el Patronato de Archivos, Bibliotecas y Museos de Zaragoza en el mes de junio de 1939. Del mismo modo, comunica que la Biblioteca de la Universidad de Zaragoza es la entidad que dispone del dinero obtenido en la Fiesta del Libro, puesto que cuando se celebró la misma, Javierre ya se encontraba en su nuevo destino de Barcelona con el fin de organizar el Servicio en esa ciudad ${ }^{114}$.

Las cuentas justificadas, incluyendo ingresos, gastos e inversión en volúmenes durante los años 1936 y 1937 se enviaron meses más tarde. ${ }^{115}$

\section{Conclusiones}

El Servicio de Lecturas del Soldado de la Biblioteca de la Universidad de Zaragoza, primero creado en la España nacional, dirigía sus objetivos tanto a desarrollar la lectura como terapia de los heridos y convalecientes como a mantener y reforzar su moral mediante una bibliografía dirigida y controlada.

La sede zaragozana se convirtió en una de los más dinámicas y eficaces, junto con Sevilla, en gran parte debido a la capacidad gestora de Aurea Javierre. Pese a ello, la carencia de medios de transporte, la escasa implicación de buena parte de las autoridades y la falta de homogeneidad tanto en la estrategia de captación de

113 ABUZ. Correspondencia oficial. Oficio de Aurea Javierre a Javier Lasso de la Vega sobre la Fiesta de la Raza. Zaragoza 3 de enero de 1939.

114 ABUZ. Correspondencia oficial. Oficio de Aurea Javierre al Gobernador Civil de Zaragoza y Presidente del Patronato de Archivos. Bibliotecas y Museos comunicando que el dinero recaudado por la Fiesta de la Raza se encuentra en la Biblioteca de la Universidad de Zaragoza. Zaragoza, 30 de junio de 1939.

115 ABUZ. Servicio de Lecturas del Soldado. Cuentas justificadas Fiesta de la Raza octubre de 1938 con destino a la obra Lecturas para el Soldado. 27 de junio de 1939. 
fondos como en la aplicación de criterios censores, resultaron obstáculos insalvables que condujeron incluso a especular con el tránsito a otro modelo de actuación, más cercano al desarrollado por la Alemania nazi, durante la etapa de Javier Lasso de la Vega.

El Servicio experimentó dos etapas. La primera, que finaliza en 1938, estuvo dirigida por Miguel Artigas, y se caracteriza por la creación de un marco de actuación ambiguo e impreciso, la preocupación por dotar al bando nacional de un órgano que contrapesara el dinamismo del Servicio de Lecturas republicano, y la necesidad de localizar a los facultativos que permanecían en la zona controlada por los sublevados. La segunda tiene como protagonista a Lasso de la Vega desde la jefatura de archivos, bibliotecas y museos, momento en que se dota de contenidos teóricos perfectamente definidos, notoriamente influenciados por la biblioterapia anglosajona. Es en esta fase cuando la dimensión profesional de Aurea Javierre, en constante y estrecha colaboración con el propio Lasso de la Vega, alcanza una enorme notoriedad, hasta el punto de exportar su modelo organizativo a los distritos de Castellón, Lérida y, posteriormente, a Barcelona.

El impacto que tuvo su implantación sobre las actividades ordinarias de la biblioteca fue enorme, no solo por la marginación a que fueron sometidas, sino porque absorbió gran parte de la dedicación de los facultativos y del escaso presupuesto económico del que disponía, más allá de la complicada convivencia con una estructura externa, temporal y finalista.

\section{Referencias bibliográficas}

Alares López, G. (2007) Presentación. En Bergmann, Werner. Estudios sobre la tradición cultural en la zona limítrofe del Alto Aragón y Navarra. Zaragoza: Institución Fernando el Católico.

Alcalde Fernández, Á. (2010). Lazos de sangre. Los apoyos sociales a la sublevación militar en Zaragoza. La Junta Recaudatoria Civil (1936-1939). Zaragoza: Institución Fernando el Católico.

Allué, V. (2006). El Servei de Bibliotheques del Front, epopeia cultural del segle XX. Item: Revista de biblioteconomia i documentació, 44, 67-112.

Alted Vigil, A. (1984). Política del Nuevo Estado sobre el patrimonio cultural y la educación durante la Guerra Civil Española. Madrid: Dirección General de Bellas Artes y Archivos.

Benítez Marco, P. (2014) Áurea Lucinda Javierre Mur (1898-1980): su ideal feminista católico. En Cenarro, Ángela y Illion, Regine (eds.) Feminismos: contribuciones desde la historia. Zaragoza: Prensas Universitarias de Zaragoza, 159-188.

Calamita, G. (1936) El peor estupefaciente. Boletín de Educación de Zaragoza, 3.

Castro y Calvo, J. M. (1968). Mi gente y mi tiempo. Zaragoza: Librería General.

Cugueró, M.; Boada, M.T.; Allué, V. (2006). El Servei de Bibliotheques del Front: 19361939. Barcelona, Diputació de Barcelona, 1995.

Duplá Ansuátegio, A. (2012). La revista falangista Jerarqvia y el modelo imperial romano. Vasconia: Cuadernos De Historia - Geografía, 38, 813-837.

La Fiesta del Libro (1938). El Noticiero, 22 de abril de 1938.

García Ejarque, L. (2000). Historia de la lectura pública en España. Gijón: Trea. 
Gomez Andres, A. (2013). Teresa Andrés. Biografía. Valencia: Universitat de Valencia. Herráiz, I. (1937) Zaragoza ha enviado 7.000 libros para el Ejército. El Noticiero, 23 de febrero.

Kuehl Harbaugh, J. (1984) The effectiveness of bibliotherapy in teaching problem solving skills to female juvenile delinquents. A Dissertation Presented to The School of Graduate Studies Drake University. <http:/escholarshare.drake.edu/ bitstream/handle/ 2092/666/dd1984jkh.pdf?sequence=1 > [Consulta: 12/03/2015]

Lacarra, J. M. (1946). Mandatos reales navarro-aragoneses del siglo XII, Estudios Edad Media, Corona de Aragón, 2, 425-431. <www.memoriadigitalvasca.es/bitstream /10357/20065/1/106786.pdf> [Consulta: 12/02/2016]

Martínez Rus, A. (2014). La persecución del libro: hogueras, infierno y buenas lecturas (1936-1951). Gijón: Trea.

Melero, J. L. (2006). Los libros de la guerra: bibliografía comentada de la Guerra Civil en Aragón (1936-1949). Zaragoza: Rolde de Estudios Aragoneses.

Poemas de la Falange eterna. (1938) Santander: Aldus.

Torres, M. (2011). La Biblioteca de la Universidad de Madrid durante la Segunda República y la Guerra Civil. Tesis doctoral. Madrid: Universidad Complutense.

Vall Casas, A. (1990). Los bibliotecarios de las bibliotecas para pacientes en España: evolución histórica de una profesión. Anales de Documentación, 12, 303-319

Valls Taberner, F. (1934). Espagne. En Guide International des Archives. Europe. París: Institute International de Cooperation Intellectuelle de la Société de Nations. 70-96. 